\title{
Nanomedicine for increasing the oral bioavailability of cancer treatments
}

\author{
Alessandro Parodi ${ }^{1,2^{*},}$, Polina Buzaeva ${ }^{1}$, Daria Nigovora', Alexey Baldin ${ }^{3}$, Dmitry Kostyushev ${ }^{2,4}$, \\ Vladimir Chulanov ${ }^{2,4,5}$, Lyudmila V. Savvateeva ${ }^{1}$ and Andrey A. Zamyatnin $\mathrm{Jr}^{1,2,3,6^{*}}$
}

\begin{abstract}
Oral administration is an appealing route of delivering cancer treatments. However, the gastrointestinal tract is characterized by specific and efficient physical, chemical, and biological barriers that decrease the bioavailability of medications, including chemotherapeutics. In recent decades, the fields of material science and nanomedicine have generated several delivery platforms with high potential for overcoming multiple barriers associated to oral administration. This review describes the properties of several nanodelivery systems that improve the bioavailability of orally administered therapeutics, highlighting their advantages and disadvantages in generating successful anticancer oral nanomedicines.
\end{abstract}

Keywords: Oral nanomedicine, Cancer treatment, Biological barriers

*Correspondence: aparodi.sechenovuniversity@gmail.com;

zamyat@belozersky.msu.ru

${ }^{1}$ Institute of Molecular Medicine, Sechenov First Moscow State Medical

University, 119991 Moscow, Russia

Full list of author information is available at the end of the article to the material. If material is not included in the article's Creative Commons licence and your intended use is not permitted by statutory regulation or exceeds the permitted use, you will need to obtain permission directly from the copyright holder. To view a copy of this licence, visit http://creativecommons.org/licenses/by/4.0/. The Creative Commons Public Domain Dedication waiver (http://creativeco mmons.org/publicdomain/zero/1.0/) applies to the data made available in this article, unless otherwise stated in a credit line to the data. 


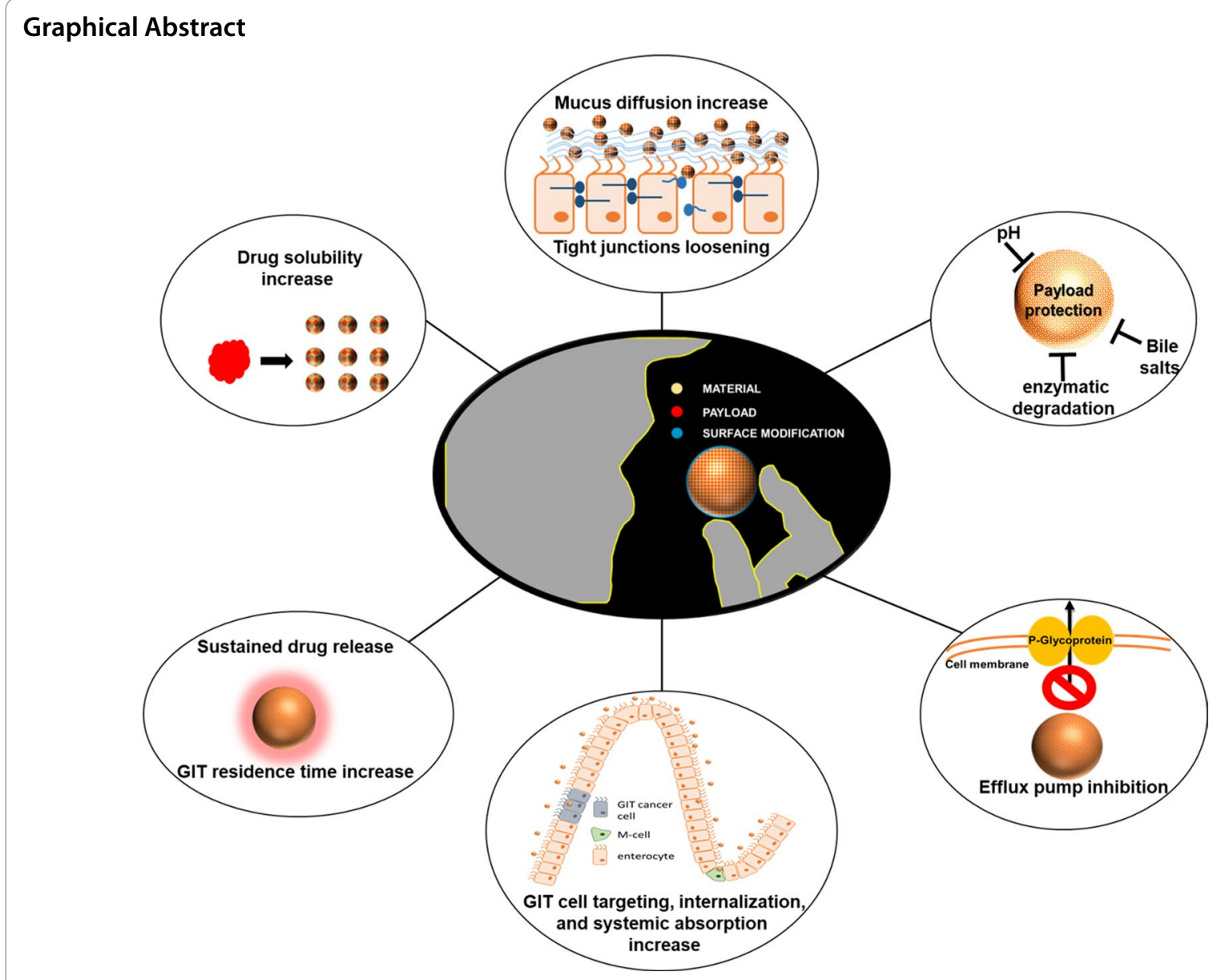

\section{Introduction}

The primary factor determining drug pharmacokinetics and proper concentration at the target site is the administration route. Despite known drawbacks like low drug bioavailability, high degradation, and intestinal and hepatic metabolism, oral treatments have always been considered the most convenient way to deliver a pharmaceutic. This clinical dogma is generally applied to any pathological condition, and most of the approved therapeutics on the market are designed for oral administration [1] (Fig. 1). Oral chemotherapy could be a game-changer for improving patients' condition while allowing regulation of therapeutic doses without significantly impacting off-target tissues [2]. Finally, oral drug administration is perceived more favorably by patients, particularly compared to infusions and other parenteral administration routes that characterize cancer treatment [3].

Some benefits of oral chemotherapy over standard drug administration routes remain to be proven [4], and patient self-medication has some flaws. For example, shortened hospitalization time decreases clinical evaluation of patient condition and unreported side effects may be overlooked [5, 6]. Self-medication can lead to overdose [7], while other issues are connected to individual differences in drug absorption [8]. Finally, oral drugs are more expensive than traditional parenteral formulations, mitigating the economic benefits of reduced hospitalization time. However, over $90 \%$ of patients prefer oral therapeutics [9], and oral chemotherapy may improve palliative treatment in the late stages of disease [10], further prolonging patient lifespan. Traditionally, oral drug delivery is more efficient for treatments based on small molecules. High molecular weight molecules and most new biologic therapeutics are poorly suitable for this kind of administration due to multiple and heterogeneous biological barriers characterizing the gastrointestinal tract (GIT). For example, oral bioavailability of intact proteins can vary 


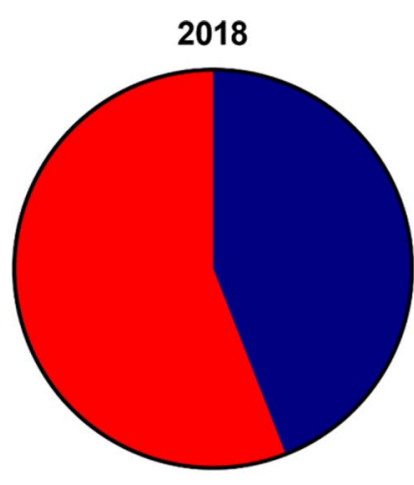

Total $=59$

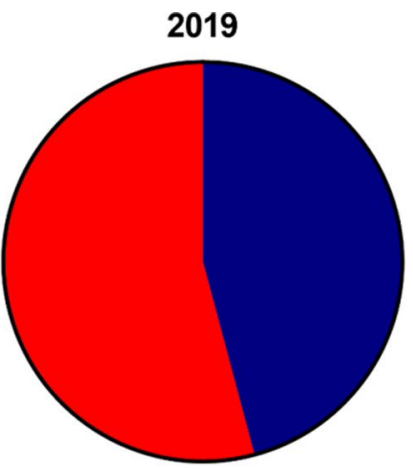

Total $=48$

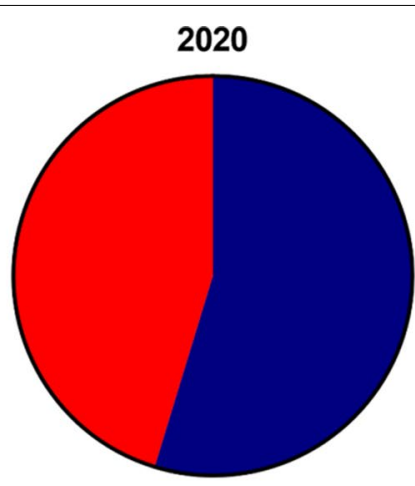

Total $=53$

Oral approved therapeutics

- Other therapeutics

Fig. 1 FDA-approved therapeutics in 2018-2020. The graph shows the fraction of approved therapeutics designed for oral delivery (red) compared to therapeutics developed for other administration routes (blue). Source: www.fda.gov

from 0.1 to $1 \%$ of the administered dose $[11,12]$. In addition, the GIT is particularly efficient at decreasing bioavailability of chemotherapeutics, since these molecules are usually affected by low solubility, inactivation under acidic conditions, and low diffusion across cell membranes of GIT epithelium. Also, chemotherapeutics are often substrates of gastric and hepatic metabolic enzymes [13] and transporters like P-glycoprotein (P-gp), which further decrease their bioavailability [14]. New advances in material science paved the way to increase the repertoire of orally administered cancer therapeutics. In particular, nanomedicine and the vast number of carriers for it [15] show solid potential to enhance oral drug delivery of small and high molecular weight molecules. Orally administered nanocarriers can protect the payload from unfavorable biological and chemical conditions of the GIT while favoring controlled drug release. Moreover, oral nanocarriers also enhance targeting towards specific GIT cellular phenotypes, diffuse through the mucous layer, and increase drug bioavailability, avoiding first-pass metabolism.

This review focuses on nanotechnologies tested for oral chemotherapy, highlighting their characteristics for overcoming specific and multiple GIT biological barriers. Some of these barriers also need to be addressed when treating GIT tumors, common and lethal diseases affecting nearly every section of this organ system. Before describing recent examples of oral nanomedicine, a general description of GIT biological barriers and the techniques used to measure intestinal absorption is paramount.

\section{GIT biological barriers}

Different tissue, cellular, physical, and biological components regulate GIT barrier function. The buccal cavity may be an optimal site for drug administration, considering its mildly acidic environment and high submucosal and sublingual space vascularization. However, the transit time of pharmaceutics in the buccal cavity is usually very brief. Therefore GIT remains the primary absorption site for orally administered pharmaceutics [16].

\section{Physical and chemical barriers}

The GIT is a muscular tube $6-10 \mathrm{~m}$ long. It is organized into various anatomical regions grouped into 2 two parts: the upper (mouth, pharynx, esophagus, stomach, and duodenum of the small intestine) and the lower section (jejunum and ileum of the small intestine, large intestine, and anus). Nutrient and pharmaceutic absorption varies in the different sections of the GIT. The stomach is the site where the food is broken down and is characterized by small surface area, limited nutrient (and drug) absorption, and very low $\mathrm{pH}$ (between 1.5 and 2.5) representing the first chemical barrier encountered by oral pharmaceutics sensitive to acidic $\mathrm{pH}$. However, stomach $\mathrm{pH}$ can increase significantly (up to 4-5) after a meal. The small intestine is characterized by slightly acidic $\mathrm{pH}$ (5-7.5) that increases in the large intestine (up to 8) [17]. GIT epithelium is lined with mucus, a hydrogel characterized by pores of $200 \mathrm{~nm}$ secreted by the goblet cells [18]. Mucus is a physical barrier hampering diffusion of drug molecules into systemic circulation. It is a fluid enriched in negatively charged proteins (mainly mucins) 
highly modified with proteoglycans $[19,20]$. Mucus plays a significant role in facilitating the passage of food through the GIT and protecting tissues from pathogens and low $\mathrm{pH}$ [21]. Mucus is quickly turned over and can vary in thickness $(200-800 \mu \mathrm{m})$ [22, 23], being thickest in the stomach and large intestine (colon), and thinner in the small intestine [24]. Transit time in different parts of the GIT can also significantly affect drug bioavailability, varying between a few minutes to several hours in the stomach depending on whether the person is fasted or fed. Transit time in the small intestine is typically a few hours, while in the large intestine, it can vary from $6 \mathrm{~h}$ to a several days [25]. Transit time also depends on age, gender, health state, and food intake amount of the patient. Moreover, mucus composition, transit time, and intestinal fluid composition are strongly affected by the quality and quantity of ingested food and water. All these factors can affect oral drug delivery.

\section{Biological barriers}

Enzymatic degradation is another significant biochemical barrier, particularly for biologics. Pepsin, a broad-range protease, is the main enzyme of the stomach. However, other digestive enzymes, like lipases, are also secreted, and in general, enzymatic composition varies in different GIT sections. In the small intestine, pancreatic and hepatic enzymes break down carbohydrates and nucleic acids in addition to proteins and fatty acids. Mucus is also necessary to provide the ideal environment for enteric microflora proliferation and survival that can change with age, diet, GIT location, and pathological conditions (dysbiosis) [26]. From a therapeutic perspective, the microbiome and the associated enzymatic pathways can represent an additional biochemical barrier. Understanding the different mechanisms occurring during GIT absorption is fundamental for selecting carrier material and surface properties, particularly when the payload needs protection in this environment.

The main factors that govern GIT absorption are the surface area of the tissue, tissue vascularization, water solubility, physical state (suspension, solid, or solution), and concentration of the pharmaceutical at different absorbing sites, [27]. In terms of pharmacokinetics, oral administration does not allow for fast and efficient therapeutic absorption because absorbed drug molecules are affected by the first-pass metabolism that occurs in the intestine and especially in the liver, where drugs are transported through the portal vein after reaching circulation [28]. However, some therapeutics, known as prodrugs [29], are designed to be enzymatically activated in these sites, and can be utilized to achieve proper drug efficacy. While the stomach has low absorption capacity limited to hydrophobic and non-polar drugs [17], the small intestine is the primary absorption site of the GIT [30]. The surface area of the small intestine is very high due to tissue villi and enterocyte microvilli. Additionally, the small intestine is highly vascularized and connected to the lymphatic system. Finally, in the large intestine, waste processing occurs, and absorption is limited to water [31].

The last barrier is the membrane of the cells lining the GIT. Of these, enterocytes are recognized as the main absorption elements. Nutrients and therapeutics can overcome the epithelial barrier in five distinct ways that can be grossly grouped as active and passive transport. Paracellular and transcellular diffusion are considered passive ways of transport, while receptor-mediated, carrier-mediated, and microfold cell (M-cell)-mediated passage are considered active transport. M-cells, along with enterocytes and some goblet cells, compose the follicle-associate epithelium covering Peyer's patches, lymphoid structures that are the primary immune system components of the GIT. M-cells have strong engulfment potential and sort pathogens, bacteria, and viruses destined for the components of the underlying immune system [32, 33]. Notably, much effort has been dedicated to understanding active transport mechanisms to increase absorption of different therapeutics. For example, antiviral valine esters were explicitly designed to exploit peptide transporter-1 and neutral and essential amino acid transporters $[34,35]$. The phenotypic variability of GIT epithelium is completed by stem cells forming the crypts of Lieberkühn, which reside in invaginations between villi and constantly renew the epithelial cell populations, and by Paneth cells, which secrete factors essential for microflora maintenance.

Paracellular transport mechanisms are regulated by epithelial tight junctions, adherens junctions, and desmosomes. The GIT epithelium is permeable only to very small molecules and ions $(8-13 \AA)$, with an estimated paracellular cut-off below $2 \mathrm{~nm}$. When the junctions open, this passage can increase to $18 \mathrm{~nm}$, while the underlying layers are impermeable to elements larger than 13-15 $\mathrm{nm}$ [36]. Transcellular transport is regulated by the hydrophilic nature of the transported molecule. While hydrosolubility is essential for drug interaction with the GIT epithelium, polarity can inhibit drug diffusion through the cellular membrane. Therefore, to exploit the transcellular pathway, therapeutics must be amphiphilic. According to the Biopharmaceutics Classification Scheme, therapeutics are classified into four different groups as a function of membrane permeability and aqueous solubility [37]. 


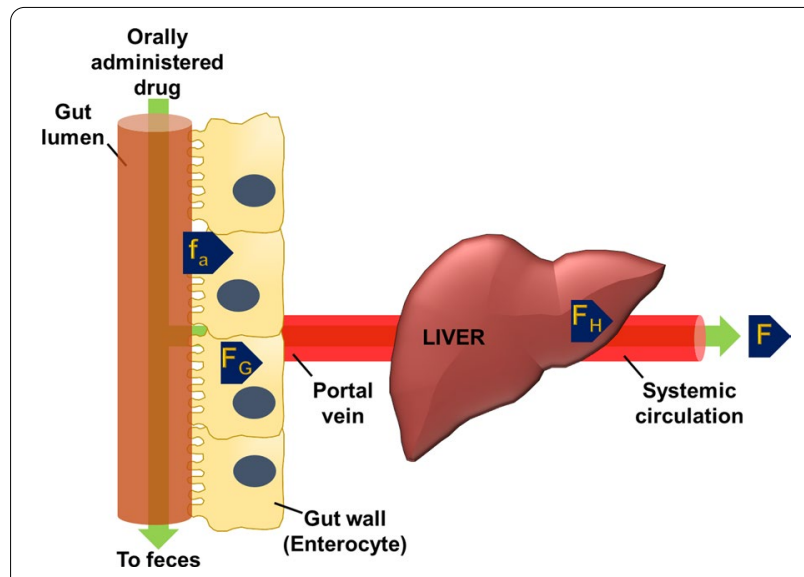

Fig. 2 Calculation of the net bioavailability of orally administered therapeutics. Net bioavailability (F) can be extrapolated by calculating the product of the fraction of the drug that overcomes the gastrointestinal tract (GIT) epithelium $\left(f_{a}\right)$, the fraction of the drug that is not metabolized in the GIT $\left(F_{G}\right)$, and the fraction of the drug that is not metabolized in the liver $\left(F_{H}\right)$

This equilibrium is described by the $\log P$ value of a molecule, which is a direct measure of its liposolubility. $\log P$ is directly related to the molecule's ability to diffuse through the cell membrane and indirectly related to its ability to diffuse in GIT fluids [38]. Net oral bioavailability $(\mathrm{F})$ corresponds to the product of the fraction of the administered dose that overcomes the enterocyte membrane $(\mathrm{fa})$, the fraction that is not metabolized in the gut tissue (Fg), and the fraction that is not metabolized during hepatic first-pass metabolism (Fh) (Fig. 2). Polar molecules can cross cell membranes of enterocytes and M-cells. However, it is worth mentioning that this trafficking can be limited by the expression of transporters like P-gp, multidrug resistance protein 2, and breast cancer resistance protein in GIT epithelial cells, which sort back absorbed molecules.

A general schematic of the major biological barriers hampering oral drug delivery is shown in Fig. 3.

\section{Experimental models}

Different levels of research models are used investigate the absorption of any therapeutic in the GIT environment. Computational models have been generated to predict intestinal drug absorption [39], but unfortunately, only a few attempts were made to apply these tools to oral nanomedicine. To our knowledge, this research field is minimal but growing [40, 41].

\section{In vitro models}

Protocols based on simulated intestinal fluids are widely used to investigate the potential of nanomedicine for oral drug delivery. Loaded particles are usually incubated in these buffers to evaluate their stability and drug

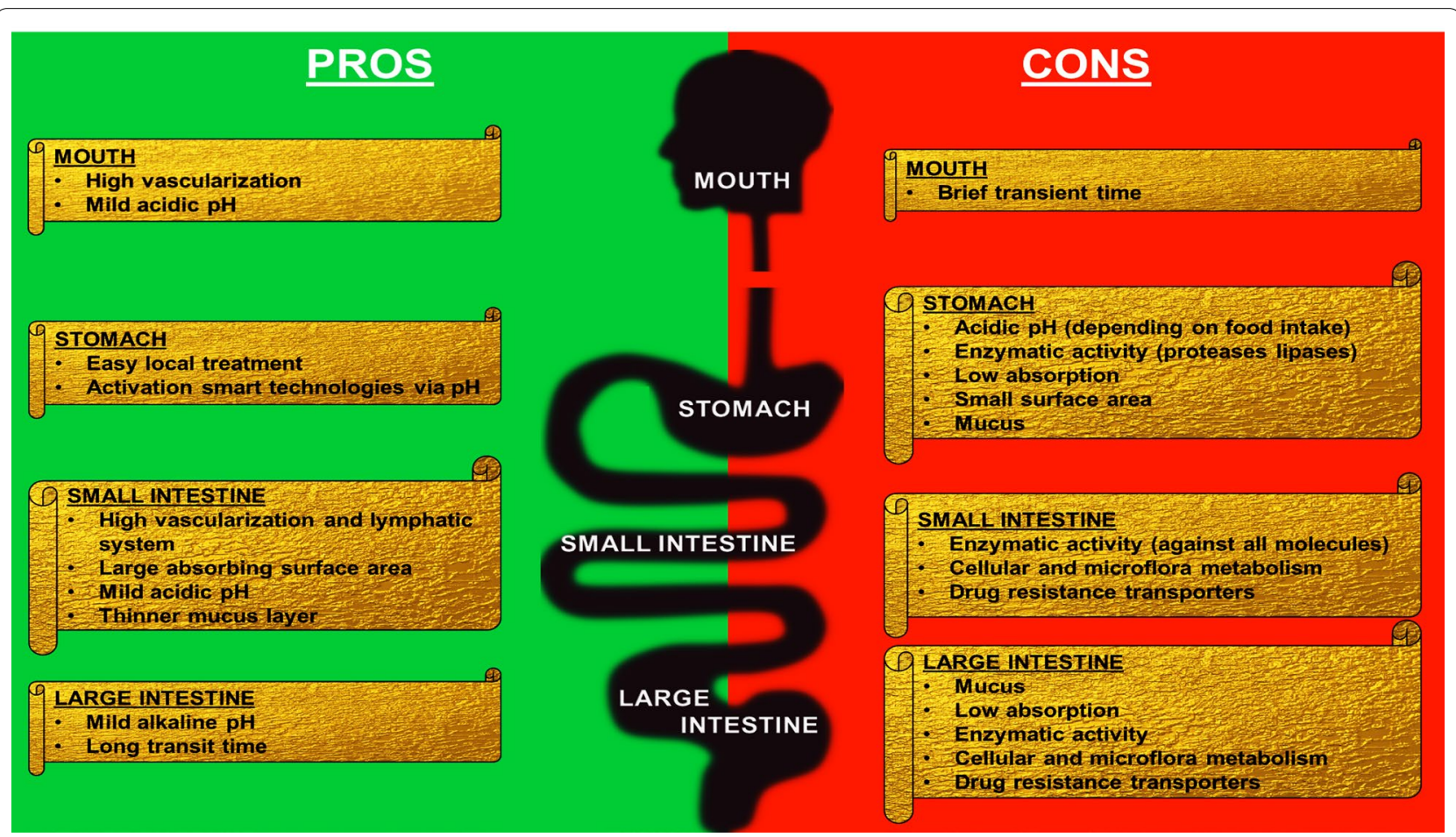

Fig. 3 Advantages and disadvantages for pharmaceutical absorption in each GIT section 
release properties in the GIT. Simulated GIT fluids are characterized by specific $\mathrm{pH}$, bile salt, and enzyme concentrations to represent the different compartments of the gastrointestinal system. Some procedures describe protocols for generating gastric fluids that simulate fasted and fed conditions, since $\mathrm{pH}$ and enzymatic content can vary significantly in these states [42]. The human epithelial colorectal adenocarcinoma cell line Caco-2 is the most common in vitro cellular model of the GIT epithelium. These cells are easy to culture and form microvilli and monolayers connected with tight junctions, as confirmed by the high values of transepithelial electric resistance measurements (260-450 $\Omega$ / $\mathrm{cm}^{2}$ ) [43]. Caco-2 cells also express most of the surface markers of the GIT epithelium, including metabolizing enzymes, transporters, and P-gp [44]. Molecular and particle trafficking through this reconstructed in vitro epithelial barrier is usually measured by seeding Caco-2 in transwell systems, though many researchers prefer to co-culture this cell line with other cells like HT29 [45, 46], an adenocarcinoma cell line that can differentiate in mucus-secreting cells after treatment with methotrexate. Transwell systems also allow generation of more complex models by seeding Caco-2 in the upper chamber and lymphocytes isolated from Peyer's patches of mice in the lower chamber. This cellular conditioning induces Caco-2 to perform transcytosis. A similar effect is obtained by co-culturing Caco-2 with human Burkitt's lymphoma Raji B cells [47] (Fig. 4). From a physiological standpoint, classical in vitro cell culture is not very informative since tissue organization and the vascular, lymphatic, and nervous systems are missing. However, it can provide preliminary data about toxicity on the GIT epithelium and the ability of the therapeutics (and nanoparticles) to overcome the epithelial monolayer and affect its barrier function.

Organ-on-a-chip systems represent further advances in the field, and in this case, they are referred to as guton-a-chip (GoC). In $\mathrm{GoC}$, the goal is to increase system complexity, including elements like microbiota and endothelial and immune cells [48, 49]. Other GIT features like shear and peristaltic forces can also be applied [50]. The basic unit of a GoC is composed of a chamber divided by a semipermeable soft porous membrane into two channels representing the intestinal lumen and the underlying vasculature. The channels can be connected to peristaltic pumps to imitate flow conditions and perform the treatments (Fig. 5) [50]. These systems allow for characterization under optic and fluorescent microscope and for controlling temperature, $\mathrm{O}_{2}, \mathrm{CO}_{2}, \mathrm{pH}$, and transepithelial electric resistance (TEER) measurements, and are ideal for investigating epithelial perfusion under more complex conditions [51].

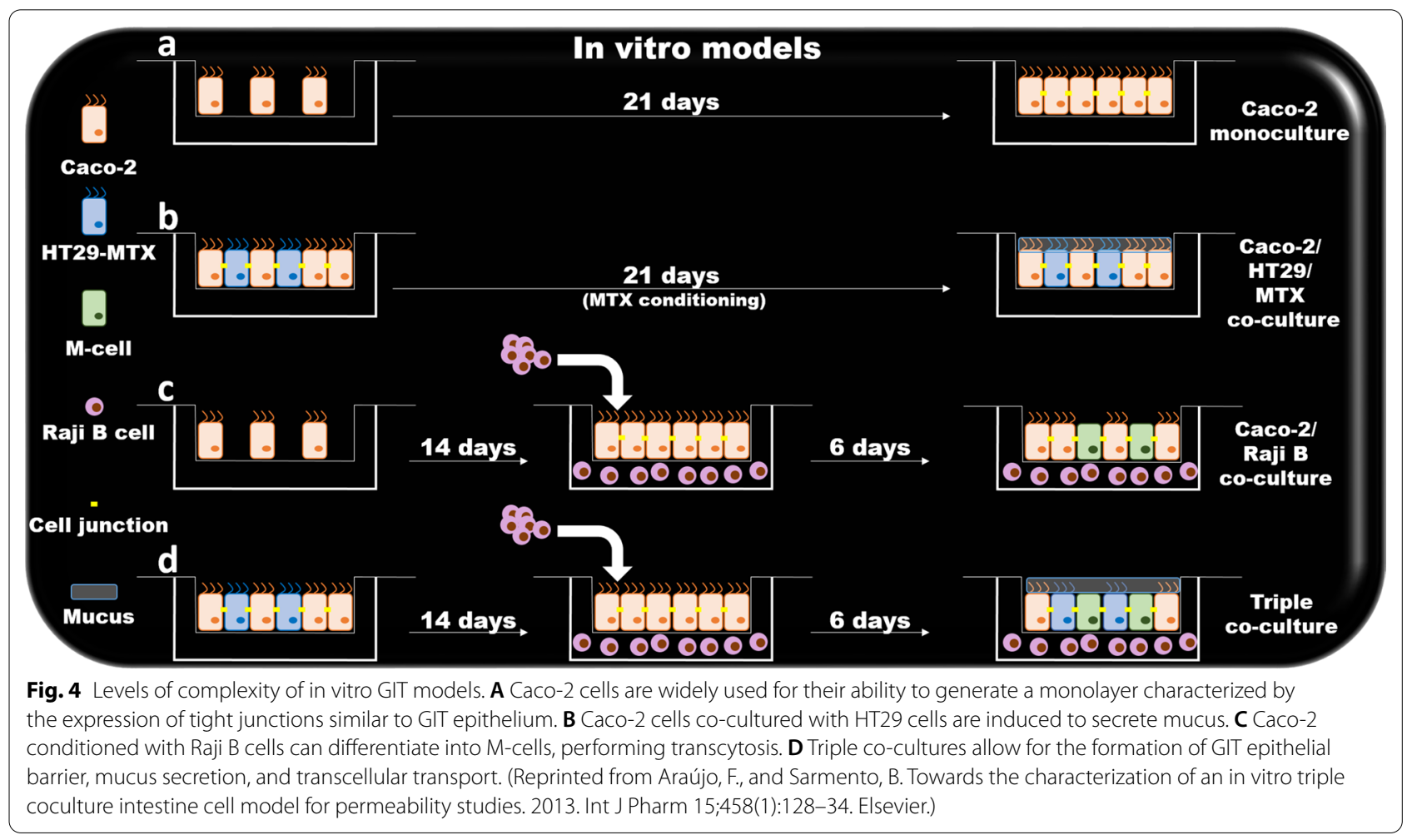




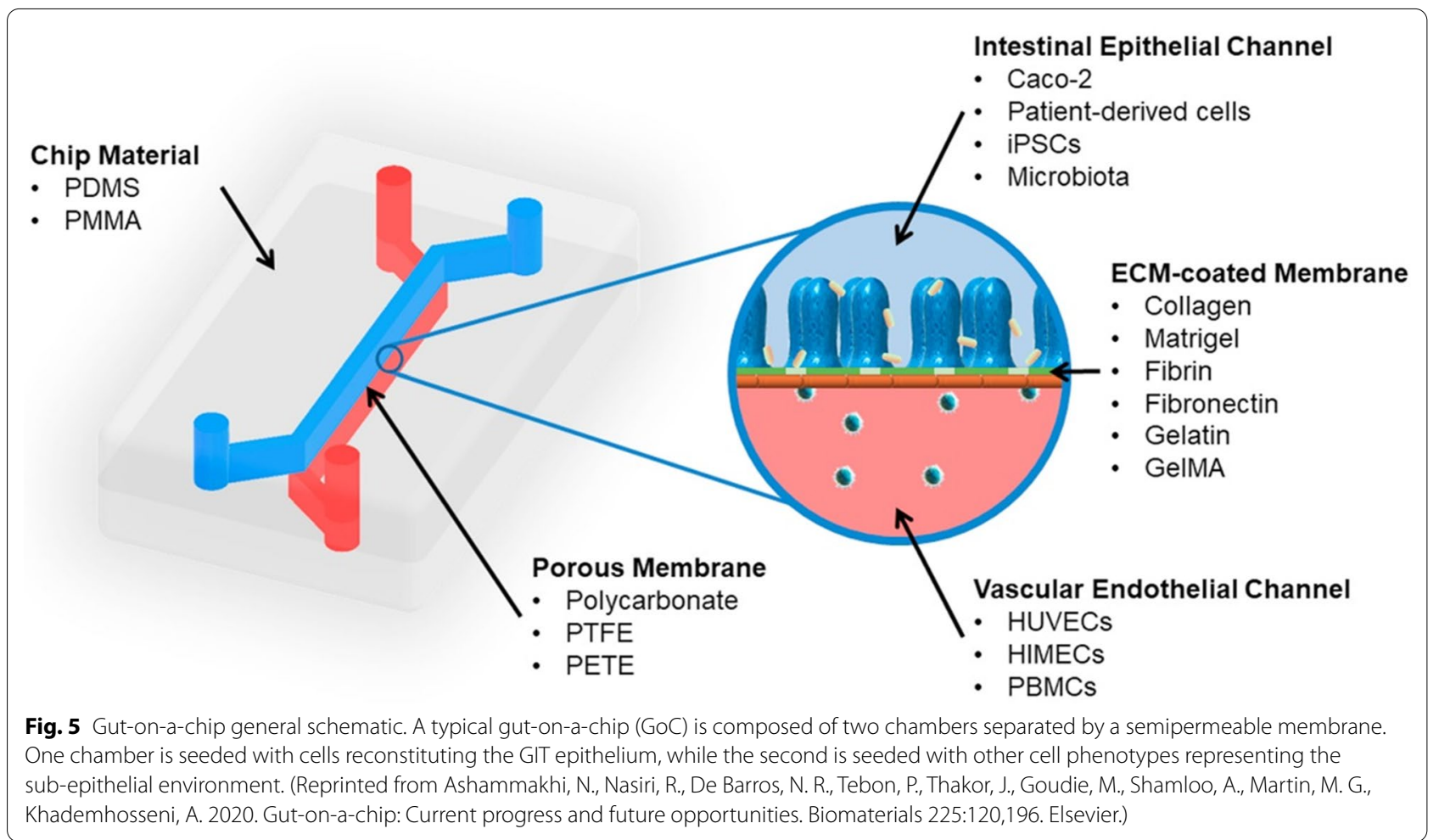

\section{Ex-vivo, in situ, and in vivo models}

Ex-vivo models are based on isolating different sections of the intestine, and barrier integrity and absorption can be investigated in everted [52] and non-everted [53] segments. In the first case, to investigate barrier integrity, molecules or particles of interest are administered outside the tissue that, after eversion, exposes the GIT mucosa. In the second case, instead, the, intestines are ligated and filled with the molecule of interest and absorption is investigated by analyzing the drug content in intestinal tissue. These models preserve the mucus layer and allow simple investigation of paracellular distribution in specific parts of the GIT, particularly in the small intestine, although some damage occurs during tissue preparation. However, from a physiological standpoint, interrupting blood and lymphatic systems and the lack of nervous system components are significant drawbacks of ex vivo systems in pharmacological studies [54].

In situ protocols are performed in vivo by isolating intestinal sections via ligation and locally injecting the molecule of interest. Absorption is then measured in the blood of the subject animal. The physiology of the animal is preserved and absorption can be investigated in specific GIT sections. We recommend the following reviews for more in-depth information of ex situ and in situ procedures [36, 52, 54]. However, these techniques need some surgical and technical skills that can be avoided with classic in vivo experiments in which the therapeutic is administered as a bolus. These protocols totally recapitulate the clinical scenario, since no or minor stress is imparted to the animal during drug administration, and the therapeutics are transported through the whole GIT. New advances in material science have allowed the generation of nanoparticles with increased adherence to the GIT wall. Eventually, accumulation and trafficking of these molecules can be observed through multiple imaging techniques, including in vivo imaging systems and magnetic resonance imaging [55].

\section{Increasing oral bioavailability through nanomedicine}

The use of nanoparticles to enhance oral drug delivery is supported by recent evidence that highlights their versatility and ability to load different therapeutics. Encapsulation can provide a means to increase drug solubility, while particle surface properties can facilitate the penetration of the physical barriers of mucus and epithelial cell membranes. Drug encapsulation also protects the therapeutic payload from the harsh gastric chemical and enzymatic conditions and allows controlled release, which may be helpful for maintaining proper therapeutic concentrations. Finally, 
nanocarriers allow co-encapsulation of more than one molecule to simultaneously deliver synergistic pharmaceutics that work more precisely together than when administered singularly. Carriers can be generated from biological and organic materials, although inorganic materials and hybrid systems are also routinely tested for this purpose. Each material provides unique features to favor drug encapsulation, protection, and GIT translocation in the bloodstream and the lymphatic system. These features will be described in the following sections, emphasizing the nanoparticle properties that allow negotiation of the GIT biological barriers.

\section{Polymers}

This section refers to organic polymers like polyglycolic acid, polymethylmethacrylate, polylactic acid (PLA), poly(lactic-co-glycolic acid) (PLGA), and poly( $\varepsilon$ caprolactone). These materials have the great advantage of being almost entirely biocompatible and resistant to the GIT environment. Methacrylic co-polymer coating (Eudragit) is commonly used to stabilize oral pharmaceutical formulations like tablets and capsules, and more recently, they have been shown to improve stability of liposomal formulations [56]. For this reason, they are commonly used to generate hybrid technologies to improve oral delivery properties of other materials. However, polymeric nanoparticle synthesis can be expensive, and industrial production can be challenging [57]. PLGA is a frequently investigated class of polymer in this field, and its surface functionalization versatility allows for synthesizing nanoparticles that target specific intestinal transporters, favoring their absorption. For example, when functionalized with carnitine, PLGA nanoparticles can efficiently target $\mathrm{Na}^{+}$-coupled organic cation/carnitine transporter 2 (OCTN2), expressed in the lumen of the small intestine, to enhance the delivery of paclitaxel [58]. Characterization of this system and in vitro experiments demonstrated that the success of this kind of targeting depends on several factors. Increasing carnitine concentration on the particles' surface did not increase their cellular uptake and eventually inhibited their internalization in vitro, demonstrating that optimizing the surface density optimization of the targeting molecule is essential. Secondly, the authors demonstrated that knowledge of the transporter mechanism is necessary to generate efficient oral nanomedicine. In this case, since OCTN2 co-transports carnitine and $\mathrm{Na}^{+}$ in a 1:1 ratio, particle uptake increased in the presence of $\mathrm{Na}^{+}$. This evidence was confirmed in vivo by administering free and encapsulated paclitaxel via in situ single-pass perfusion. When the therapeutic was administered via PLGA nanoparticles modified with carnitine, higher drug bioavailability was observed; this was also because particle internalization reduced the effect of P-gp, which strongly inhibits paclitaxel. Optimized $\mathrm{Na}^{+}$concentration further improved the process, while free carnitine significantly decreased particle uptake, indicating that these particles must be administered in parallel, with diets containing a certain amount of sodium and no carnitine for reaching optimal therapeutic performance. Finally, the group discovered that much of the absorption occurred in the lymphatic system, suggesting that a certain number of particles can overcome the epithelial barrier via a caveolin-mediated pathway, probably due to OCTN2 receptor recycling. PLA nanoparticles are FDA approved and show high biocompatibility, safety, and sustained drug release [59]. However, when designed for oral administration, they are affected by low GIT absorption, poor mucus penetration, and rapid elimination, though optimizing the surface chemistry of PLA nanoparticles with cell-penetrating peptides [59] can mitigate these drawbacks. Similar benefits are achieved with PLA nanoparticle PEGylation, as demonstrated by the significantly increased bioavailability of encapsulated raloxifene hydrochloride compared to the free administered drug [60], potentially enhancing the usability of this therapeutic for breast cancer prevention [61].

Pharmacokinetic properties of hydrophobic chemotherapeutics like paclitaxel can be improved by modifying PLA particles with folic acid, since the GIT epithelium has significant expression of folate receptors [62]. Folate improved particle diffusion in the mucus layer and particle internalization in GIT epithelial cells. A further modification of this kind of delivery platform with D-alpha-tocopheryl polyethylene glycol (PEG) succinate increased paclitaxel encapsulation efficiency, decreased its release rate, and significantly reduced P-gp drug efflux [63]. These particles were also successfully tested for their efficacy and safety in a rat model of lung cancer.

Polycaprolactone (PCL) is another polymer for generating biocompatible nanoparticles for delivering different chemotherapeutics, including docetaxel [64], cisplatin [65], methotrexate [65], and paclitaxel [66]. PCL nanoparticles have been shown to increase the oral bioavailability of ellagic acid, a natural molecule that has potent anti-cancer, anti-angiogenic, and anti-metastatic activity, but is affected by high hydrophobicity and poor GIT absorption. Encapsulating ellagic acid increased its bioavailability over three-fold by increasing its hydrophilicity and lymphatic absorption via M-cells [67]. 


\section{Inorganic materials}

Currently, several inorganic materials can be used to generate nanoparticles with different uses and properties. Some of these properties perfectly fit with the scope of engineering nanoparticles for oral administration. Generally, inorganic nanoparticles are considered more stable at body temperatures and acidic conditions, even though some materials are entirely soluble at low $\mathrm{pH}$. Between them, silica nanoparticles were significantly investigated to improve oral delivery of therapeutics. Silica is generally considered biocompatible [68] and easy to modify, and can be made porous to accommodate different payloads. US FDA and European FSA have approved silica as a food and drug additive, and its oral intake is generally considered safe [69]. Amorphous silica has a low dissolution rate at low $\mathrm{pH}$ while it degrades faster at higher $\mathrm{pH}$, providing a perfect tool to exploit the GIT $\mathrm{pH}$ gradient. Because silica porosity can be easily adjusted, silica nanoparticles can accommodate different payloads [70] including biologics and, after encapsulation, the payload is highly protected from digestive enzymes [71]. Recently, a silica nanostructure was proposed to generate a floating drug delivery system allowing for long gastric retention in the presence of sodium bicarbonate and vegetal polymers [72]. A similar technology based on aluminum silicate was designed to improve the delivery of methotrexate, which has a very short half-life [73]. The benefits of silica for generating oral delivery systems depend on its ability to interact with very hydrophobic molecules to improve their solubility and intestinal absorption due to increased particle internalization while reducing drug efflux phenomena. In vitro, silica did not affect cell membranes and tight junctions of a reconstructed GIT epithelial barrier. Although more toxicological data are necessary, recent observations indicate that silica is better tolerated when orally administered than when it is given intravenously or intraperitoneally.

Another element that can be used for oral nanomedicine is selenium. Its anti-cancer properties are well known, and physiological levels of selenium have high cancer prevention potential [74]. However, clinical selenium use is hampered by significant side effects [75], and the use of selenium nanoparticles is restricted as a supplement for oral administration [76]. Biogenic selenium nanoparticles were synthesized via bacterial production in Bacillus licheniformis and tested in vitro for their anti-cancer effects and toxicity. In vivo, compared to commercial selenium supplements, these nanoparticles demonstrated reduced toxicity, probably due to the biological origin of the nanoparticles that increased their biocompatibility. However, when the authors tested the particles in vivo, compared to commercial selenium sources, they saw reduced drug absorption that could partially explain reduced systemic toxicity [76].

\section{Polysaccharides}

Polysaccharides are amphiphilic molecules and provide good wetting properties to overcome the mucus barrier, in addition to their natural ability to encapsulate anti-tumor therapeutics. They are isolated from different biological sources, including animals (chitosan), algae (alginate), plants (pectin), and bacteria (dextran).

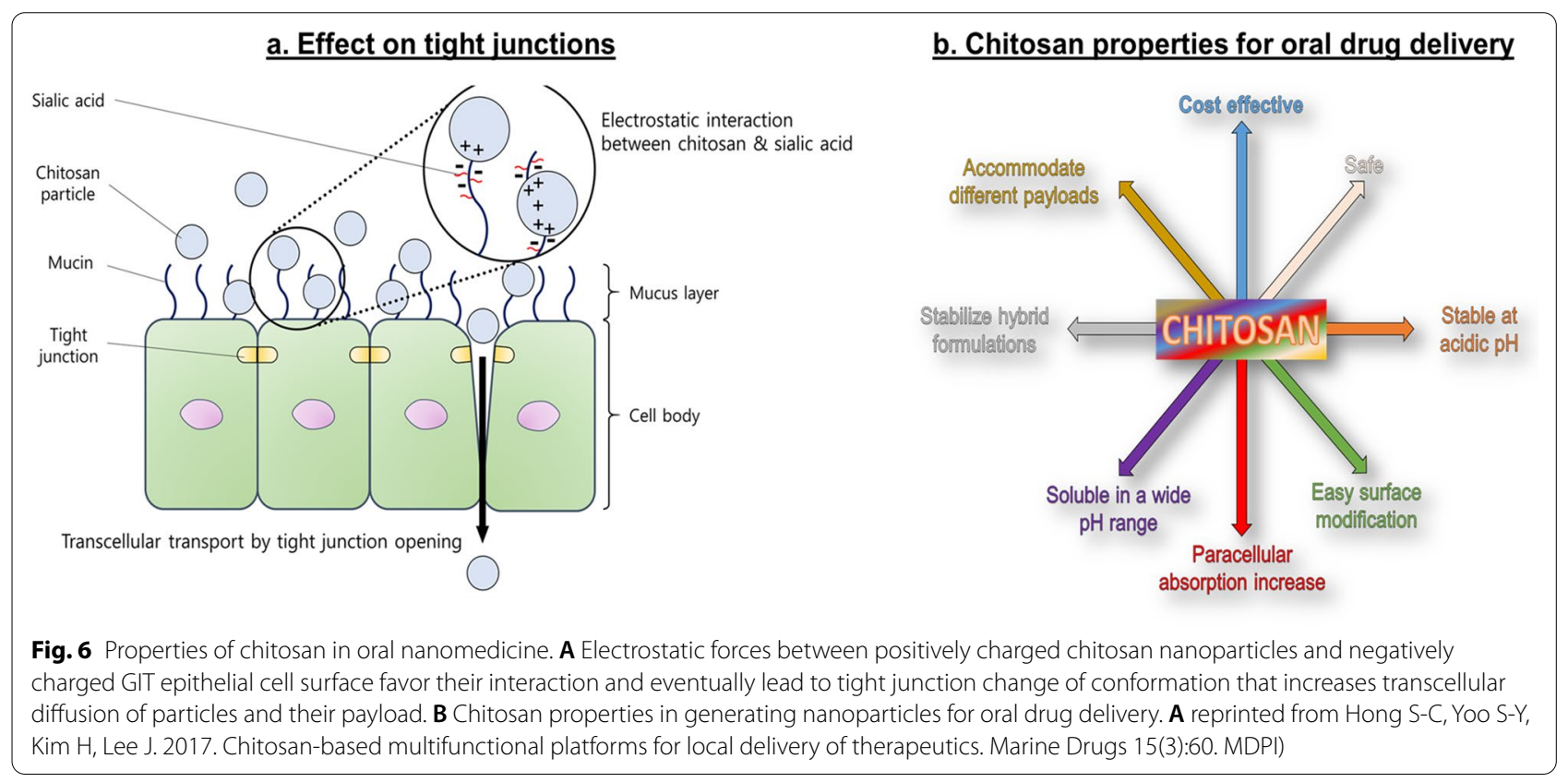


They are biocompatible, generally easy to manipulate on the nanoscale, and extensively used for pharmacological formulations. As with other nanoformulations, polysaccharide nanoparticles demonstrate the ability to inhibit efflux pump activity [77], and in some cases, they are preferentially absorbed via M-cells [14]. Chitosan represents the gold standard of this class of materials because it was shown to favor tight junction relaxation and increase paracellular absorption [78-80] (Fig. 6a). This phenomenon is most prominent at low $\mathrm{pH}$ [81], when chitosan protonation occurs, destabilizing the junctions, but chemical modifications like methylation can extend these properties and increase chitosan solubility in a broader range of $\mathrm{pH}$ [82]. Chitosan is also partially soluble in water, generating hydrogel formulations that can accommodate different payloads, including biologics like proteins and siRNA [83]. Chemical modification and hybridization with other materials may make chitosan the most promising material for oral nanomedicine (Fig. 6b). Chitosan nanoparticles modified with acrylonitrile and arginine groups have been shown to enhance curcumin bioavailability [84]. Acrylonitrile provides a hydrophobic skeleton to accommodate this hydrophobic therapeutic while inducing nanoparticle self-assembly, while arginine enhances solubility, increases cell surface interaction, and prolongs residence time and controlled drug release in the GIT [84]. Other hybrid systems based on chitosan modification will be discussed in the following sections.

Another polysaccharide extensively used to generate oral nanomedicine is cyclodextrin, which very efficiently encapsulates hydrophobic drugs (e.g., docetaxel), and can block efflux pump activity [85]. Cyclodextrin nanoparticles significantly increased paclitaxel bioavailability when orally administered, and the drug was detected for $24 \mathrm{~h}$ in the bloodstream after administration [86], providing significant benefits in treating a murine model of sarcoma. Similar delivery advantages were observed when orally administered tamoxifen was encapsulated in guar gum nanoparticles [87].

\section{Protein-based carriers}

Protein carriers formulated from poly-amino acid chains, gelatin, collagen, casein, and albumin are a few examples of this category. These molecules have amphipathic properties and are ideal for accommodating payloads with different chemical and physical features. M-cells could represent a natural gate for protein nanoparticle transport across the GIT epithelium since they translocate antigens to the underlying lymphoid tissues [88]. Theoretically, protein nanoparticles can easily break down under the action of GIT proteases. The pioneering work of Liu et al. demonstrated that orally administered

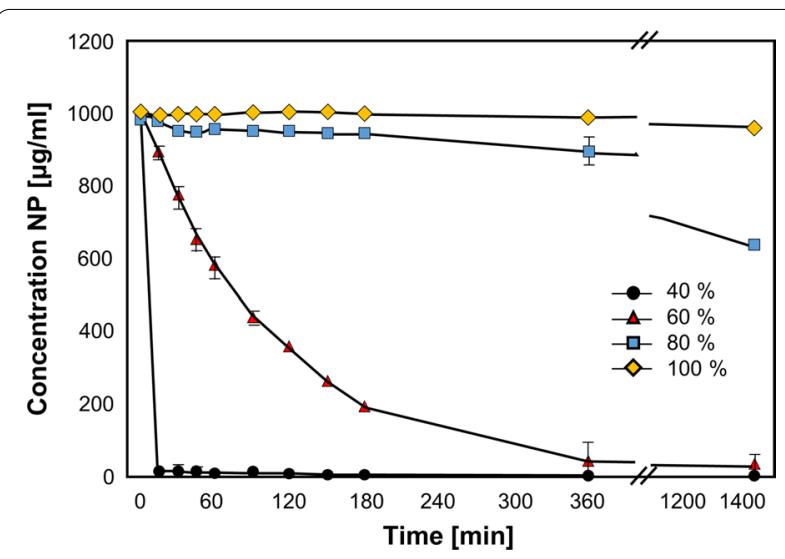

Fig. 7 Effects of varying amounts of the cross-linker glutaraldehyde in preventing trypsin degradation of albumin nanoparticles. The figure was reprinted from Langer, K., Anhorn, M.G., Steinhauser, I., Dreis, S., Celeb, D., Schrickel, N., Faust, S., Vogel, V. 2008. Human serum albumin (HSA) nanoparticles: Reproducibility of preparation process and kinetics of enzymatic degradation. Int J Pharm 347(102):109-117. Elsevier

protein-based pharmaceuticals can be stabilized by coadministering proteases inhibitors [89], even though, to the best of our knowledge, no such protocols have been used to improve cancer treatments. Thus, stabilizing agents like cross-linkers or hybrid formulations were tested for achieving successful drug delivery. Albumin nanoparticles, for example, are extremely sensitive to pepsin and trypsin, but glutaraldehyde cross-linking can protect them from these enzymes [90] and overcome this biological barrier (Fig. 7).

The synthetic protocols used to generate protein nanoparticles can affect their stability against enzymatic degradation. Albumin carriers generated via desolvation are more prone to pepsin degradation than particles synthesized via emulsification, probably due to differential access of pepsin to cleavable peptide bonds [91]. In addition, hybridizing proteins with other materials can increase protein stability in the GIT. For example, coating casein/zein nanoformulations with the carbohydrate pectin was shown to protect the particles while increasing their loading ability (e.g., curcumin) [92].

Moreover, the surface of protein carriers allows multiple sites of chemical modification to increase accumulation of these particles at the intestinal epithelium level, where they can release the payload or, in the case of GIT tumors, improve carrier specificity to target tumor cells. Interestingly, nanoparticles composed of apotransferrin and lactoferrin efficiently increased doxorubicin accumulation in hepatic cancer after oral delivery even though the authors did not investigate the particle/payload absorption mechanism [93]. However, this work is 
important because it raised doubts about the translational power of current in vivo models, since absorption in rodents may be more efficient than in humans [94].

As in many cases discussed in this review, generation of nanomedicine for oral drug delivery is often driven by the need to enhance oral bioavailability of a therapeutic agent. For example, resveratrol, a hydrophobic polyphenol found in wine, shows significant therapeutic effects in cardiovascular disease treatment and cancer prevention. However, its bioavailability when orally administered is very low (less than 5\%) due to its high excretion rate and hepatic and intestinal metabolism [95]. Also, intestinal flora can modify the structure of this molecule via hydrogenation. However, resveratrol can be easily loaded into milk casein nanoparticles via hydrogen and hydrophobic bonds $[96,97]$. Casein is a perfect molecule for generating nanomedicine for oral delivery, since this protein is commonly found in food and can be easily engineered at the nanoscale. Penalva et al. [98] demonstrated high efficiency of resveratrol encapsulation in casein nanoparticles, with controlled release of this therapeutic in vitro when the particles were incubated in reconstructed gastric and intestinal fluids. In vivo casein nanoparticles showed excellent propensity to interact and disperse in mucus, increasing in vivo resveratrol bioavailability.

\section{Hybrid lipid nanoparticles}

Lipid nanoparticles (i.e., liposomes, solid lipid nanoparticles) enhance hydrophobic drug encapsulation solubility, but when used for oral administration, they are often engineered in hybrid formulations to increase their stability in the GIT environment. However, some studies indicate that when interacting with bile salts, liposomes can generate vesicles and micelles that can be absorbed in the upper section of the GIT via transcytosis [99, 100]. Hybrid lipid-polymeric nanoparticles have been designed to increase the oral bioavailability of cabazitaxel [101], which is affected by the typical GIT absorption issues of taxanes (low solubility, high metabolism, P-gp activity). The polymeric structure represented by poly( $\varepsilon$-caprolactone) protect against acidic environment of the stomach, while the lipid component (a medium-chain triglyceride) increases drug loading yield. Finally, a positively charged octadecylamine and neutrally charged polyethylene oxide surface modifications increase mucus layer penetration and cellular uptake, as demonstrated in vitro and in vivo. M-cells probably favor absorption of these particles, since lymphatic transport of cabazitaxel was detected. This approach allows significantly increased oral bioavailability and efficacy of this

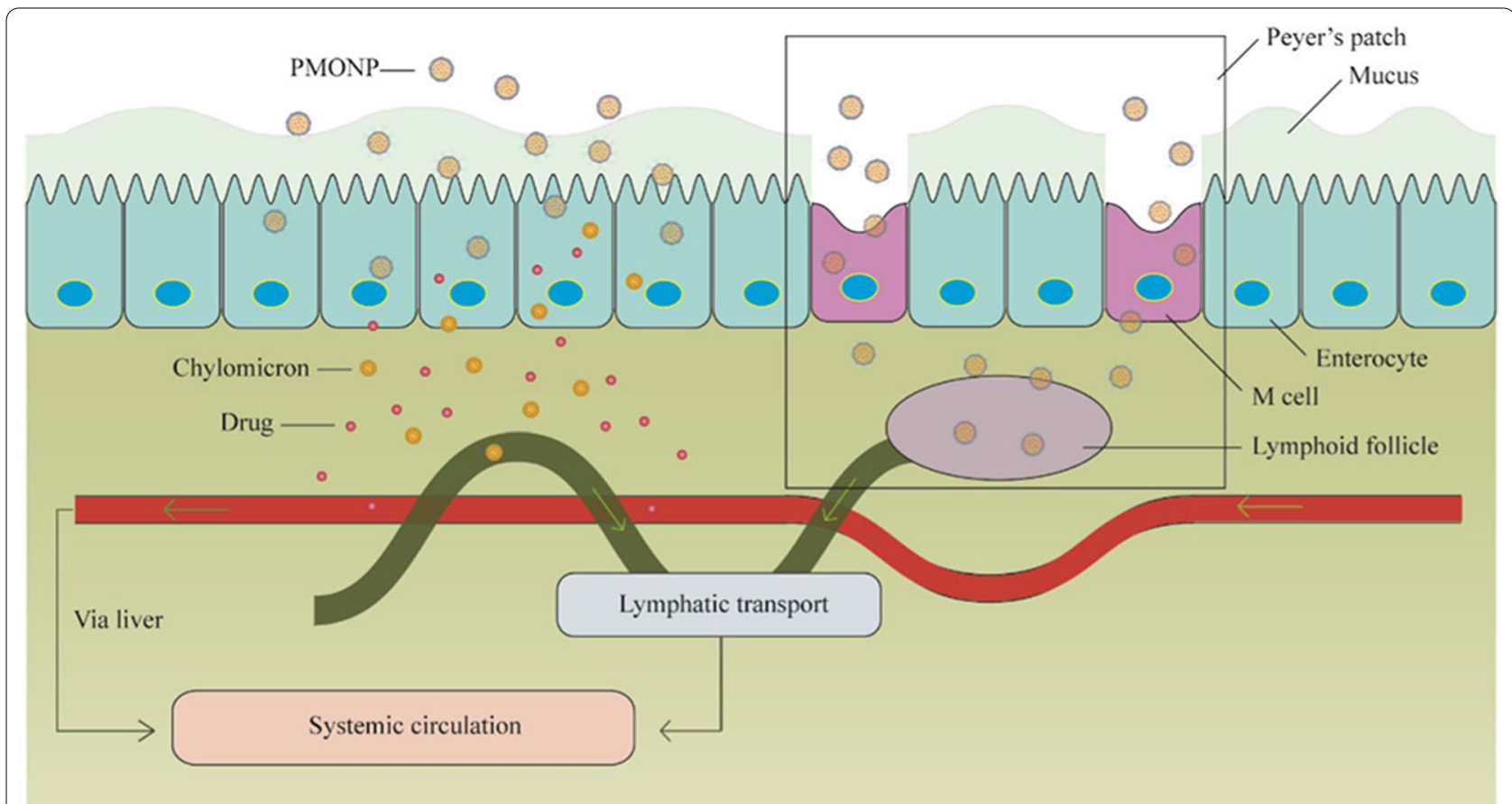

Fig. 8 Polymer-lipid hybrid nanoparticle (PMONP) mechanism of absorption. Particle absorption occurs, respectively, via transcellular transport favored by the positive charge of the particles and via M-cell-mediated internalization that increases systemic and lymphatic bioavailability of the payload cabazitaxel. The figure was reprinted from Ren T., Wang Q., Xu Y., Cong L., Gou J., Tao X., Zhang Y., He H., Yin T., Zhang H., Zhang Y., Tang X. 2018. Enhanced oral absorption and anticancer efficacy of cabazitaxel by overcoming intestinal mucus and epithelium barriers using surface polyethylene oxide (PEO) decorated positively charged polymer-lipid hybrid nanoparticles. J. Control Release 269:423-38. Elsevier 
chemotherapeutic, as shown in vivo in a subcutaneous model of hepatic cancer (Fig. 8).

The group of Dr. Chen developed polymer(pegylated PLGA)-stabilized lipid nanoparticles to increase the oral bioavailability of berberine, a vegetal molecule with numerous therapeutic properties that include anti-neoplastic activity [102]. Oral administration could accelerate its clinical translation, but its chemical structure does not allow efficient absorption. Previous attempts to improve oral bioavailability [103] using liposomal systems failed due to particle degradation in the GIT [102]. For this reason, a PEGylated hybrid lipid-PLGA system was generated to increase particle drug encapsulation, stability, and interaction with the GIT epithelium. The PEG surface modification was crucial to overcoming the mucus barrier and, compared to free drug administration, the authors demonstrated high intestinal absorption in vivo. Similarly, the group of Dr. Cho [104] applied a layer of N-carboxymethyl chitosan to solid lipid nanoparticles that are known to increase the solubility of hydrophobic drugs, provide sustained release of the payload at the $\mathrm{pH}$ seen in intestines [105-107], and favor absorption through the lymphatic system, bypassing hepatic firstpass metabolism [106, 108]. N-carboxymethyl chitosan coating increased carrier and payload (curcumin) protection in the stomach environment, eventually favoring its absorption in the mesenteric lymph nodes.

Nucleic acids like short interfering RNAs (siRNA) and long interfering RNAs are a class of biologics that would greatly benefit from oral delivery, but are sensitive to the harsh gastric environment and cannot cross the GIT epithelium [109]. Ball et al. generated particles composed of a lipid mixture, including the amphiphilic lipidoid $306 \mathrm{O} 13$ (to complex the RNA), cholesterol, DSPC, and PEGylated lipids, to increase particle stability and mucus penetration of siRNA [110]. They demonstrated that optimal PEG concentration was crucial for successful siRNA delivery across the mucus barrier, confirming the importance of optimizing the density of surface modifications. Despite high delivery efficiency in vitro, stability of these particles was affected by pepsin and bile salts that enhanced their aggregation and degradation, respectively. These data highlighted the importance of analyzing all the factors that compose the GIT environment, since the protease pepsin can still affect the therapeutic efficiency of lipid nanoparticles. In vivo, pepsin concentration in the stomach drastically differs before and after meals, and is reduced during fasting [110]. Testing these conditions, the authors showed higher particle stability and increased small intestine and colon targeting with strong accumulation within intestinal crypts, where the particles could deliver the siRNA to immune cells. This finding highlights the importance of diet and administration time in overcoming GIT barriers.

\section{Bioinspired systems}

In this section, we discuss carriers that can be grown or isolated in nature without extensive bottom-up synthetic procedures and that can be exploited for drug delivery purposes. Of these, microorganisms and exosomes have particular features that are functional for developing oral drug delivery while maintaining precise characteristics on the nanoscale. Microorganisms represent the last frontier for the development of oral nanomedicine since they can specifically target M-cells $[111,112]$ and potentially be transported to the diseased sites through the lymphatic system $[111,113]$. This approach was utilized by the group of Dr. Zhang, who developed a technique to load nanoparticles in yeast and exploit yeast $\beta$-glucan capsules to target dectin-1 to M-cells [114]. The external layers and cytoplasm of yeast were chemically eliminated and replaced with therapeutic nanoparticles via electrostatic forces. The carriers were cationic polyethyleneimine loaded with the anti-inflammatory therapeutic indomethacin and paclitaxel; alternatively, iron oxide nanoparticles were used to target the system for magnetic resonance imaging. The authors demonstrated that M-cells mediated transport of yeast loaded with nanoparticles into the lymphatic system, where the particles were recognized and eventually transported to inflamed sites and tumors by macrophages while maintaining significant anti-inflammatory and anti-tumor properties [115].

Microorganisms can also serve as the perfect basis for developing orally administrable cancer vaccines [116]. Cysteine-rich variant-specific surface proteins (VSP) were shown to determine the resistance and colonization of Giardia lambia in the GIT tract of mammals. Modifying the surface of retrovirus-like particles with these proteins determined their GIT stability and allowed immunization against influenza virus hemagglutinin (HA). More importantly, this vaccine induced an immune response against a transgenic mesothelioma tumor expressing HA. VSP coating was also shown to increase the immunogenicity of the system, providing a natural adjuvant for immunization. The authors demonstrated that this approach could provide a solid protocol for generating an oral vaccine for cancer when directed against proper antigens [117].

Similarly, live attenuated Salmonella bacteria were coated with cationic polymeric nanoparticles condensed with DNA to generate an oral cancer vaccine [118]. The 
a

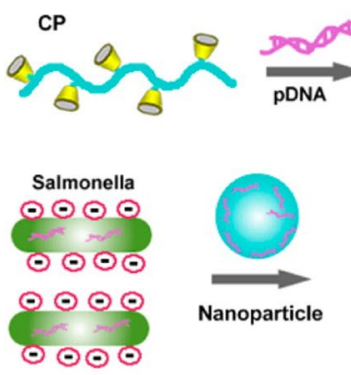

d

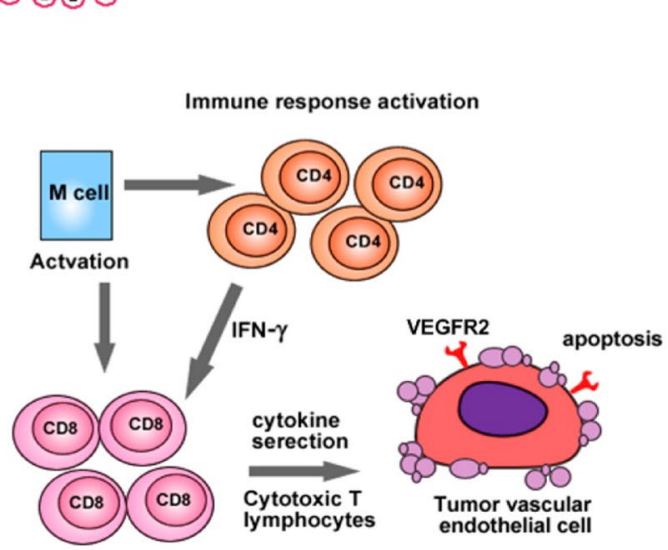

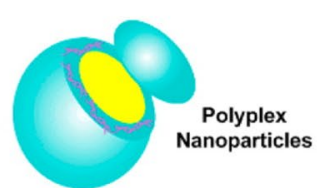

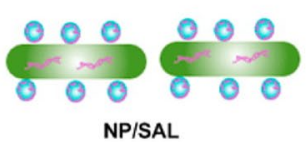

NPISAL

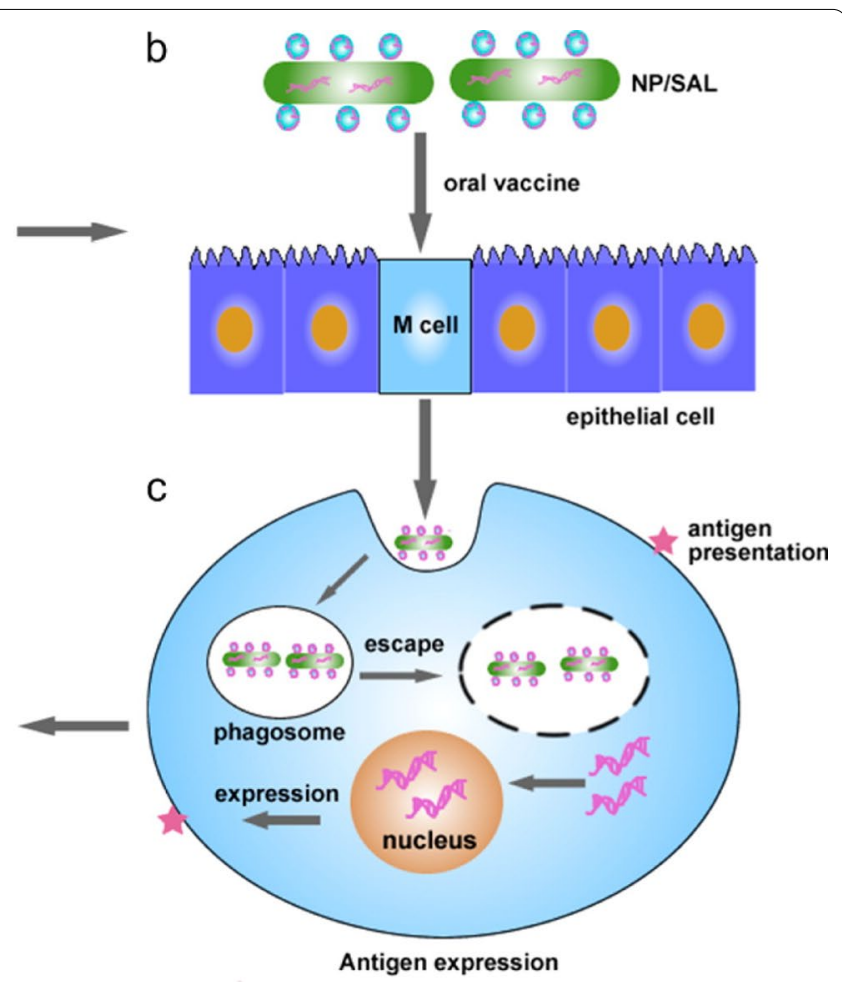

Fig. 9 Synthesis and working mechanism of polyplex nanoparticle-coated Salmonellae. A Polyplex nanoparticles are synthesized by complexing plasmid DNA encoding VEGFR2 with the cationic polymer polyethylenimine and used to coat attenuated Salmonella bacteria. B The system is internalized by M-cells and, $\mathbf{C}$ after endosomal escape, the expression of VEGFR2 on the surface of these cells can $\mathbf{D}$ induce an anti-tumor immune response via T cell activation. The figure was reprinted from Hu Q., Wu M., Fang C., Cheng C., Zhao M., Fang W., Chu P.K., Ping Y., and Tang G. 2015. Engineering nanoparticle-coated bacteria as oral DNA vaccines for cancer immunotherapy. Nano Lett 15(4):2732-9. ACS Publications

system was designed to be stable at low $\mathrm{pH}$ and escape phagosome entrapment after internalization to deliver its immunogenic cargo to the cytoplasm. Salmonella bacteria were coated spontaneously via electrostatic interactions between the positively charged nanoparticles and the negatively charged surface of the bacteria. The authors demonstrated that this coating efficiently protected the attenuated bacteria from the gastric environment, favoring their distribution in the blood and the lymphatic tissue. The bacteria also efficiently mediated anti-cancer immunity via $\mathrm{T}$ cell activation $(\mathrm{CD} 4$ and CD8) and cytokine secretion. Immune system activation occurred due to VEGFR2 antigen expression on phagocytic cells after particle escape from the endosomal compartment (Fig. 9).

Milk exosomes [119-121] possess the necessary attributes for generating safe oral nanomedicine, since these molecules are part of everyday diet, can be easily isolated [120], and are stable at low pH [122]. Milk exosomes showed high efficacy in vitro and allowed for controlled drug (paclitaxel) release in different reconstructed gastric fluids [123]. The nanoformulation of paclitaxel in milk exosomes was stable after several weeks at $-80{ }^{\circ} \mathrm{C}$, a fundamental characteristic for its future translational application. In vivo, the loaded exosomes demonstrated significant tumor-killing properties against a subcutaneous lung cancer model, and no adverse effects were correlated with either the carrier or the drug. Interestingly, the authors detected slight tumor growth inhibition upon administration of exosomes only, attributing these effects to some potential anti-tumoral molecules present in the exosome formulation, like complex human milk-derived $\alpha$-lactalbumin and oleic acid [124]. Even though the absorption mechanism was not completely elucidated, a previous report demonstrated that the exosomes could target different organs, including liver, spleen, kidney, and pancreas, when orally administered. The research in this field is very active and various foods, like grapes, 
can be viable sources of exosomes, increasing the repertoire of oral nanomedicine platforms [125].

\section{Nanodelivery systems for the treatment of GIT tumors} GIT tumors are common, often lethal diseases, affecting nearly every section of this organ system. When designing oral nanomedicines for these anatomical sites, it is essential to consider particle stability when targeting the lower GIT and particle adhesion properties when targeting the upper GIT. Oral mucositis is a common condition in cancer patients and often limits the continuity of anticancer therapies, forcing physicians to resolve this issue before continuing other treatments. PLGA nanoparticles were recently developed for treating mouth lesions caused by chemotherapy [126]. They were used to locally deliver rebamipide, a very effective therapeutic against

Table 1 Oral nanomedicine for increasing anti-cancer drug bioavailability

\begin{tabular}{|c|c|c|c|c|}
\hline & Nanoparticles (NP) & Targeted cancer / tissue & Therapeutic outcomes & Refs. \\
\hline \multirow[t]{7}{*}{ 1. Polymers } & Carnitine coated PLGA NP & - & Increased paclitaxel BA & {$[58]$} \\
\hline & Chitosan coated PLGA NP & $\begin{array}{l}\text { Oral mucositis induced by chemo- } \\
\text { therapy }\end{array}$ & Increased oral cavity residence time & [118] \\
\hline & PLGA NP & Oral cavity cancer & Increased local docetaxel delivery & [119] \\
\hline & Pegylated PLA NP & Breast cancer prevention & Increased raloxifene hydrochloride BA & {$[60,61]$} \\
\hline & Pegylated PLA NP & Lung cancer & Increased paclitaxel BA & {$[63]$} \\
\hline & $\begin{array}{l}\text { Hyaluronic acid coated pegylated } \\
\text { PLGA NP }\end{array}$ & Colon cancer & $\begin{array}{l}\text { Increased PTC209 delivery and Inhib- } \\
\text { ited cancer stem cell proliferation }\end{array}$ & {$[123]$} \\
\hline & PCL NP & - & Increased ellagic acid & {$[67]$} \\
\hline \multirow[t]{2}{*}{ 2. Inorganic materials } & Aluminum silicate & - & $\begin{array}{l}\text { Increased methotrexate release } \\
\text { properties }\end{array}$ & [64] \\
\hline & Selenium NP & Prostate cancer & $\begin{array}{l}\text { Reduced side effects and increased } \\
\text { tumor growth inhibition }\end{array}$ & [67] \\
\hline \multirow[t]{3}{*}{ 3. Polysac } & $\begin{array}{l}\text { Chitosan modified with acrylonitrile } \\
\text { and arginine }\end{array}$ & - & Increased curcumin bioavailability & [74] \\
\hline & Cyclodextrin micelles & Sarcoma & $\begin{array}{l}\text { Increased docetaxel BA and tumor } \\
\text { reduction }\end{array}$ & {$[76]$} \\
\hline & Guar gum (GG) NPs & - & $\begin{array}{l}\text { Increased mammary gland targeting, } \\
\text { tamoxifen BA, and decreased liver } \\
\text { toxicity }\end{array}$ & [77] \\
\hline \multirow[t]{4}{*}{ 4. Protein } & Pectin coated casein/zein NP & - & $\begin{array}{l}\text { Enhanced curcumin bioavailability } \\
\text { (BA) }\end{array}$ & [82] \\
\hline & Apotransferrin and lactoferrin NP & Hepatocellular carcinoma & $\begin{array}{l}\text { Enhanced doxorubicin BA and } \\
\text { decreased liver nodule number }\end{array}$ & [83] \\
\hline & Milk casein NP & - & $\begin{array}{l}\text { Increased resveratrol BA than free } \\
\text { administered drug }\end{array}$ & {$[88]$} \\
\hline & Polydopamine NPs & - & $\begin{array}{l}\text { Increased gastric targeting and local } \\
\text { xanthatin delivery }\end{array}$ & [120] \\
\hline \multirow[t]{5}{*}{ 5. Lipid nanoparticles } & Hybrid lipid-poly( $\varepsilon$-caprolactone) NP & $\begin{array}{l}\text { Subcutaneous model of hepatic } \\
\text { cancer }\end{array}$ & $\begin{array}{l}\text { Increased cabazitaxel BA and tumor } \\
\text { growth inhibition }\end{array}$ & [92] \\
\hline & Hybrid polymer-lipid NP & - & Increased berberine bioavailability & [93] \\
\hline & Chitosan coated solid lipid NP & - & Increased curcumin bioavailability & [95] \\
\hline & $\begin{array}{l}\text { Amphiphilic and pegylated lipids and } \\
\text { cholesterol }\end{array}$ & - & $\begin{array}{l}\text { Increased siRNA delivery to immune } \\
\text { cells }\end{array}$ & [101] \\
\hline & Squalene NP & Colon cancer & $\begin{array}{l}\text { Increased paclitaxel delivery and } \\
\text { tumor killing properties }\end{array}$ & {$[122]$} \\
\hline \multirow[t]{4}{*}{ 6. Bioinspired systems } & $\begin{array}{l}\text { Chimeric Virus-like Particles (VLPs) } \\
\text { decorated with VSP }\end{array}$ & HA-expressing tumor & $\begin{array}{l}\text { Increased immune response against } \\
\text { HA-expressing mesothelioma }\end{array}$ & [107] \\
\hline & $\begin{array}{l}\text { Live attenuated salmonella coated } \\
\text { with polymeric particles }\end{array}$ & Melanoma & $\begin{array}{l}\text { Increased immune response against } \\
\text { VEGFR2 }\end{array}$ & [108] \\
\hline & Yeast loaded polymeric nanoparticles & Subcutaneous breast cancer & $\begin{array}{l}\text { Increased paclitaxel delivery via } \\
\text { macrophages }\end{array}$ & [110] \\
\hline & Milk exosomes & Subcutaneous lung cancer model & $\begin{array}{l}\text { Increased tumor killing properties } \\
\text { and safety }\end{array}$ & {$[115]$} \\
\hline
\end{tabular}


oral mucositis. This drug can be formulated as a mouth wash; however, encapsulation can prolong its residence time in the mouth. The particles were about $100 \mathrm{~nm}$ to increase their surface/volume ratio, and they were coated with chitosan hydroxypropyltrimonium chloride to enhance delivery. The positive surface charge of these particles increased their interaction with the mucus in saliva, since mucin proteins are negatively charged. The particles were tested in vitro for their ability to interact with mucin and in vivo for efficacy and increased residence time in the buccal cavity. PLGA nanoparticles have also been designed to deliver docetaxel locally for treating mouth and tongue tumors [127].

The high adhesion properties of polydopamine nanoparticles [128] inspired the generation of a new delivery system to target gastric mucosa and locally delivered the plant-derived anti-cancer molecule xanthatin [129]. This carrier was chosen for its ability to load xanthatin and to adhere to the gastric mucosa. Kotolevets et al. designed a new nanoformulation of paclitaxel in squalene nanoparticles. The synthesis was based on the chemical conjugation of the drug with triterpene and further particle self-assembly, providing a platform with very efficient loading capability [130]. In vitro, the particles demonstrated high cytostatic activity and pro-apoptotic power against different cancer cell lines, including colorectal cancer cells. Also, the particles showed high stability in reconstructed gastric and intestinal fluids with minimal loss of the therapeutic payload. In vivo, orally administered nanoparticles decreased growth of colon cancer compared to free drug administration. The authors showed that drug encapsulation decreased efflux activity of the cancer cells against the therapeutic while increasing its internalization.

Finally, it is worth mentioning the work of $\mathrm{Xu}$ et al. [131], who generated oral nanomedicine to revert the stemness of colon cancer, one of the primary causes of its progression and metastatic spread. This system was composed of polymeric nanoparticles (PEGylated PLGA) coated with hyaluronic acid, a polysaccharide shown to efficiently target tumor markers like CD44 and CD168. The particles were loaded with PTC209, an inhibitor of B cell-specific Moloney murine leukemia virus integration site 1; the particles inhibited cancer stem cell proliferation, and showed targeting, efficacy, and safety in vitro and in an in vivo orthotopic model of colon cancer. A list of the nanoplatforms discussed in this section and their properties in increasing the oral bioavailability of anticancer drugs is shown in Table 1.

\section{Conclusions}

Absorption is the limiting factor for developing efficient oral chemotherapy, particularly for new high molecular weight molecules like biologics $[132,133]$. Patient adherence to the treatment poses a significant issue for clinicians. Several initiatives, including smartphone applications [134] and educational programs [135] to increase patient awareness about oral chemotherapy, provided promising results for introducing these therapeutics in the clinic. Many investigations are routinely performed to enhance the absorption of oral formulations. In particular, these studies aim to optimize drug solubility/permeability properties and inhibit P-gp and BCRP transporters [136] using excipients that can eventually favor drug absorption. For example, D- $\alpha$-tocopherol polyethylene glycol 1000 succinate and PEG-400 were shown to increase the solubility and absorption of etoposide [137], and the research on generating novel, safe solvents is very intense [138]. Nanomedicine for improving oral drug delivery is an emerging field that is a solid option for improving the current administration of chemotherapy and biologics. The scientific community has already identified some materials like chitosan, PLGA, and casein as optimal starting points for success in this field due to their abundance and cost-effective synthesis protocols. Current literature focuses on the advantages of nanomedicine in increasing drug bioavailability, overlooking the potential role of the carriers in increasing drug concentrations at the tumor site. Much work must still be done to define particle limits to overcoming the GIT epithelium, favoring drug release at its interface, and improving tumor targeting. Finally, new evidence shows that, as it occurs in the blood milieu, protein corona derived from gastric fluids and digested food can occur on orally administered nanodelivery systems, potentially affecting their targeting properties and colloidal stability [139].

\section{Abbreviations \\ GIT: Gastrointestinal tract; GoC: Gut-on-a-chip; PLGA: Poly(lactic-co-glycolic acid); OCTN2: Organic cation/carnitine transporter 2; P-gp: P-glycoprotein; PEG: Polyethylene glycol; HA: Hemagglutinin.}

\section{Acknowledgements}

Not applicable.

\section{Authors' contributions}

AP: conceptualization; $A P, P B, D N$, and DK: writing the article; $A B$, visualization; LVS and VC: review and editing; AAZJ: supervision and funding. All authors read and approved the final manuscript. 


\section{Funding}

This research was funded by the Russian Science Foundation (Grant \#

21-75-30020).

\section{Availability of data and materials}

Not applicable.

\section{Declarations}

Ethics approval and consent to participate

Not applicable.

\section{Consent for publication}

We have included 9 figures. For 6 of them, copyright permission from the copyright holder was necessary. We have mentioned this in the manuscript with proper citations.

\section{Competing interests}

The authors declare that they have no competing interests.

\section{Author details}

${ }^{1}$ Institute of Molecular Medicine, Sechenov First Moscow State Medical University, 119991 Moscow, Russia. ${ }^{2}$ Sirius University of Science and Technology, 1 Olympic Ave, 354340 Sochi, Russia. ${ }^{3}$ Belozersky Institute of PhysicoChemical Biology, Lomonosov Moscow State University, 119992 Moscow, Russia. ${ }^{4}$ National Medical Research Center of Tuberculosis and Infectious Diseases, Ministry of Health, 127994 Moscow, Russia. ${ }^{5}$ Department of Infectious Diseases, Sechenov University, 119991 Moscow, Russia. ${ }^{6}$ Faculty of Health and Medical Sciences, University of Surrey, Guildford GU2 7X, UK.

\section{Received: 19 August 2021 Accepted: 21 October 2021}

Published online: 30 October 2021

\section{References}

1. Administration UFaD. Novel drug approvals for 2018. 2018. https:// www.fda.gov/drugs/new-drugs-fda-cders-new-molecular-entitiesand-new-therapeutic-biological-products/novel-drug-approvals-2018. Accessed 20 Apr 2021.

2. Schoener C, Peppas N. Oral delivery of chemotherapeutic agents: background and potential of drug delivery systems for colon delivery. J Drug Delivery Sci Technol. 2012;22(6):459-68.

3. Liu NF, Brown AS, Folias AE, Younge MF, Guzman SJ, Close KL, et al. Stigma in people with type 1 or type 2 diabetes. Clin Diabetes. 2017;35(1):27-34.

4. Weingart SN, Zhang L, Sweeney M, Hassett M. Chemotherapy medication errors. Lancet Oncol. 2018;19(4):e191-9.

5. Jacobs JM, Ream ME, Pensak N, Nisotel LE, Fishbein JN, MacDonald JJ, et al. Patient experiences with oral chemotherapy: adherence, symptoms, and quality of life. J Natl Compr Canc Netw. 2019;17(3):221-8.

6. Bedell $\mathrm{CH}$. A changing paradigm for cancer treatment: the advent of new oral chemotherapy agents. Clin J Oncol Nurs. 2003;7:5-9.

7. Solomon JM, Ajewole VB, Schneider AM, Sharma M, Bernicker EH. Evaluation of the prescribing patterns, adverse effects, and drug interactions of oral chemotherapy agents in an outpatient cancer center. J Oncol Pharm Pract. 2019;25(7):1564-9.

8. Rowland A, Van Dyk M, Mangoni AA, Miners JO, McKinnon RA, Wiese $M D$, et al. Kinase inhibitor pharmacokinetics: comprehensive summary and roadmap for addressing inter-individual variability in exposure. Expert Opin Drug Metab Toxicol. 2017;13(1):31-49.

9. Ishitobi M, Shibuya K, Komoike Y, Koyama H, Inaji H. Preferences for oral versus intravenous adjuvant chemotherapy among early breast cancer patients. Patient Prefer Adherence. 2013;7:1201.

10. Liu G, Franssen E, Fitch MI, Warner E. Patient preferences for oral versus intravenous palliative chemotherapy. J Clin Oncol. 1997;15(1):110-5.

11. Zhou X, Po ALW. Peptide and protein drugs: II. Non-parenteral routes of delivery. Int J Pharm. 1991;75(2-3):117-30.

12. Fjellestad-Paulsen A, Höglund P, Lundin S, Paulsen O. Pharmacokinetics of 1-deamino-8-d-arginine vasopressin after various routes of administration in healthy volunteers. Clin Endocrinol (Oxf). 1993;38(2):177-82.

13. Chivere VT, Kondiah PP, Choonara YE, Pillay V. Nanotechnology-based biopolymeric oral delivery platforms for advanced cancer treatment. Cancers (Basel). 2020;12(2):522.

14. Dey M, Das M, Chowhan A, Giri TK. Breaking the barricade of oral chemotherapy through polysaccharide nanocarrier. Int J Biol Macromol. 2019;130:34-49.

15. Feng S-S, Zhao L, Tang J. Nanomedicine for oral chemotherapy. Nanomedicine. 2011;6(3):407-10.

16. Brown TD, Whitehead KA, Mitragotri S. Materials for oral delivery of proteins and peptides. Nat Rev Mater. 2020;5(2):127-48.

17. Sutton SC, Nause R, Gandelman K. The impact of gastric pH, volume, and emptying on the food effect of ziprasidone oral absorption. AAPS $\mathrm{J}$. 2017;19(4):1084-90.

18. Yildiz HM, McKelvey CA, Marsac PJ, Carrier RL. Size selectivity of intestinal mucus to diffusing particulates is dependent on surface chemistry and exposure to lipids. J Drug Target. 2015;23(7-8):768-74.

19. Maisel K, Ensign L, Reddy M, Cone R, Hanes J. Effect of surface chemistry on nanoparticle interaction with gastrointestinal mucus and distribution in the gastrointestinal tract following oral and rectal administration in the mouse. J Control Release. 2015;197:48-57.

20. Homayun B, Lin X, Choi H-J. Challenges and recent progress in oral drug delivery systems for biopharmaceuticals. Pharmaceutics. 2019;11(3):129.

21. Hua S. Advances in oral drug delivery for regional targeting in the gastrointestinal tract-influence of physiological, pathophysiological and pharmaceutical. Factors Front Pharmacol. 2020;11:524.

22. Ensign LM, Cone R, Hanes J. Oral drug delivery with polymeric nanoparticles: the gastrointestinal mucus barriers. Adv Drug Deliv Rev. 2012;64(6):557-70.

23. Boegh M, Nielsen HM. Mucus as a barrier to drug delivery-understanding and mimicking the barrier properties. Basic Clin Pharmacol Toxicol. 2015;116(3):179-86.

24. Johansson ME, Sjövall H, Hansson GC. The gastrointestinal mucus system in health and disease. Nat Rev Gastroenterol Hepatol. 2013;10(6):352.

25. Rao K, Yazaki E, Evans D, Carbon R. Objective evaluation of small bowel and colonic transit time using $\mathrm{pH}$ telemetry in athletes with gastrointestinal symptoms. Br J Sports Med. 2004;38(4):482-7.

26. Levy M, Kolodziejczyk AA, Thaiss CA, Elinav E. Dysbiosis and the immune system. Nat Rev Immunol. 2017;17(4):219-32.

27. Brunton LL, Hilal-Dandan R, Knollmann BC. Goodman \& Gilman's the pharmacological basis of therapeutics: McGraw-Hill Education New York; 2018.

28. Zhang H, Basit A, Busch D, Yabut K, Bhatt DK, Drozdzik M, et al. Quantitative characterization of UDP-glucuronosyltransferase 2B17 in human liver and intestine and its role in testosterone first-pass metabolism. Biochem Pharmacol. 2018;156:32-42.

29. Xu G, McLeod HL. Strategies for enzyme/prodrug cancer therapy. Clin Cancer Res. 2001;7(11):3314-24.

30. Huang J, Shu Q, Wang L, Wu H, Wang AY, Mao H. Layer-by-layer assembled milk protein coated magnetic nanoparticle enabled oral drug delivery with high stability in stomach and enzyme-responsive release in small intestine. Biomaterials. 2015;39:105-13.

31. Teruel AH, Pérez-Esteve É, González-Álvarez I, González-Álvarez M, Costero AM, Ferri D, et al. Smart gated magnetic silica mesoporous particles for targeted colon drug delivery: new approaches for inflammatory bowel diseases treatment. J Control Release. 2018;281:58-69.

32. des Rieux A, Fievez V, Théate I, Mast J, Préat V, Schneider Y-J. An improved in vitro model of human intestinal follicle-associated epithelium to study nanoparticle transport by M cells. Eur J Pharm Sci. 2007;30(5):380-91.

33. Gullberg E, Leonard M, Karlsson J, Hopkins AM, Brayden D, Baird AW, et al. Expression of specific markers and particle transport in a new human intestinal M-cell model. Biochem Biophys Res Commun. 2000;279(3):808-13.

34. Zhang Y, Sun J, Sun Y, Wang Y, He Z. Prodrug design targeting intestinal PepT1 for improved oral absorption: design and performance. Curr Drug Metab. 2013;14(6):675-87. 
35. Brandsch M. Drug transport via the intestinal peptide transporter PepT1. Curr Opin Pharmacol. 2013;13(6):881-7.

36. Gamboa JM, Leong KW. In vitro and in vivo models for the study of oral delivery of nanoparticles. Adv Drug Deliv Rev. 2013;65(6):800-10.

37. Amidon GL, Lennernäs $H$, Shah VP, Crison JR. A theoretical basis for a biopharmaceutic drug classification: the correlation of in vitro drug product dissolution and in vivo bioavailability. Pharm Res. 1995; 12(3):413-20.

38. Lipinski CA. Drug-like properties and the causes of poor solubility and poor permeability. J Pharmacol Toxicol Methods. 2000;44(1):235-49.

39. SIB SIoB. SwissADME.

40. Roos C, Westergren J, Dahlgren D, Lennernäs H, Sjögren E. Mechanistic modelling of intestinal drug absorption - the in vivo effects of nanoparticles, hydrodynamics, and colloidal structures. Eur J Pharm Biopharm. 2018;133:70-6.

41. Stewart AM, Grass ME. Practical approach to modeling the impact of amorphous drug nanoparticles on the oral absorption of poorly soluble drugs. Mol Pharm. 2019;17(1):180-9.

42. Patel N, Forbes B, Eskola S, Murray J. Use of simulated intestinal fluids with Caco-2 cells and rat ileum. Drug Dev Ind Pharm. 2006;32(2):151-61.

43. McClean S, Prosser E, Meehan E, O'Malley D, Clarke N, Ramtoola Z, et al. Binding and uptake of biodegradable poly-DL-lactide micro-and nanoparticles in intestinal epithelia. Eur J Pharm Sci. 1998;6(2):153-63.

44. Meunier $V$, Bourrie $M$, Berger $Y$, Fabre $G$. The human intestinal epithelia cell line Caco-2; pharmacological and pharmacokinetic applications. Cell Biol Toxicol. 1995;11(3):187-94.

45. Walter E, Janich S, Roessler BJ, Hilfinger JM, Amidon GL. HT29-MTX/ Caco-2 cocultures as an in vitro model for the intestinal epithelium: in vitro-in vivo correlation with permeability data from rats and humans. J Pharm Sci. 1996:85(10):1070-6.

46. Béduneau A, Tempesta C, Fimbel S, Pellequer Y, Jannin V, Demarne F, et al. A tunable Caco-2/HT29-MTX co-culture model mimicking variable permeabilities of the human intestine obtained by an original seeding procedure. Eur J Pharm Biopharm. 2014;87(2):290-8.

47. Araújo F, Sarmento B. Towards the characterization of an in vitro triple co-culture intestine cell model for permeability studies. Int J Pharm. 2013:458(1):128-34

48. Bein A, Shin W, Jalili-Firoozinezhad S, Park MH, Sontheimer-Phelps A, Tovaglieri A, et al. Microfluidic organ-on-a-chip models of human intestine. Cell Mol Gastroenterol Hepatol. 2018;5(4):659-68.

49. Donaldson GP, Lee SM, Mazmanian SK. Gut biogeography of the bacterial microbiota. Nat Rev Microbiol. 2016;14(1):20-32.

50. Ashammakhi N, Nasiri R, De Barros NR, Tebon P, Thakor J, Goudie M, et al. Gut-on-a-chip: current progress and future opportunities. Biomaterials. 2020;255:120196.

51. van der Helm MW, Odijk M, Frimat J-P, van der Meer AD, Eijkel JC, van den Berg A, et al. Fabrication and validation of an organ-on-chip system with integrated electrodes to directly quantify transendothelial electrical resistance. J Vis Exp JoVE. 2017. https://doi.org/10.3791/56334.

52. Alam MA, Al-Jenoobi Fl, Al-mohizea AM. Everted gut sac model as a tool in pharmaceutical research: limitations and applications. J Pharm Pharmacol. 2012;64(3):326-36.

53. Ruan L-P, Chen S, Yu B-Y, Zhu D-N, Cordell G, Qiu S. Prediction of human absorption of natural compounds by the non-everted rat intestinal sac model. Eur J Med Chem. 2006;41(5):605-10.

54. Luo Z, Liu Y, Zhao B, Tang M, Dong H, Zhang $L$, et al. Ex vivo and in situ approaches used to study intestinal absorption. J Pharmacol Toxicol Methods. 2013;68(2):208-16

55. Song Q, Jia J, Niu X, Zheng C, Zhao H, Sun L, et al. An oral drug delivery system with programmed drug release and imaging properties for orthotopic colon cancer therapy. Nanoscale. 2019:11(34):15958-70.

56. Hua S. Orally administered liposomal formulations for colon targeted drug delivery. Front Pharmacol. 2014;5:138.

57. Thanki K, Gangwal RP, Sangamwar AT, Jain S. Oral delivery of anticancer drugs: challenges and opportunities. J Control Release. 2013;170(1):15-40.

58. Kou L, Yao Q, Sun M, Wu C, Wang J, Luo Q, et al. Cotransporting ion is a trigger for cellular endocytosis of transporter-targeting nanoparticles: a case study of high-efficiency SLC22A5 (OCTN2)-mediated carnitine-conjugated nanoparticles for oral delivery of therapeutic drugs. Adv Healthcare Mater. 2017;6(17):1700165.

59. Uhl P, Grundmann C, Sauter M, Storck P, Tursch A, Özbek S, et al. Coating of PLA-nanoparticles with cyclic, arginine-rich cell penetrating peptides enables oral delivery of liraglutide. Nanomed Nanotechnol Biol Med. 2020;24:102132

60. Kala SG, Chinni S. Development of raloxifene hydrochloride loaded mPEG-PLA nanoparticles for oral delivery. Indian J Pharmaceutical Educ Res. 2021:55(1):S135-48.

61. Provinciali N, Suen C, Dunn BK, DeCensi A. Raloxifene hydrochloride for breast cancer risk reduction in postmenopausal women. Expert Rev Clin Pharmacol. 2016:9(10):1263-72.

62. Pan $X Q$, Gong YC, Li ZL, Li YP, Xiong XY. Folate-conjugated pluronic/ polylactic acid polymersomes for oral delivery of paclitaxel. Int J Biol Macromol. 2019;139:377-86.

63. Hou J, Sun E, Zhang Z-H, Wang J, Yang L, Cui L, et al. Improved oral absorption and anti-lung cancer activity of paclitaxel-loaded mixed micelles. Drug Delivery. 2017;24(1):261-9.

64. Kolluru LP, Chandran T, Shastri PN, Rizvi SA, D'Souza MJ. Development and evaluation of polycaprolactone based docetaxel nanoparticle formulation for targeted breast cancer therapy. J Nanopart Res. 2020;22(12):1-14

65. Akbari E, Mousazadeh H, Hanifehpour Y, Mostafavi E, Gorabi AM, Nejati $K$, et al. Co-loading of cisplatin and methotrexate in nanoparticle-based PCL-PEG system enhances lung cancer chemotherapy effects. J Cluster Sci. 2021. https://doi.org/10.1007/s10876-021-02101-9.

66. Witt S, Scheper T, Walter JG. Production of polycaprolactone nanoparticles with hydrodynamic diameters below $100 \mathrm{~nm}$. Eng Life Sci. 2019;19(10):658-65.

67. Mady FM, Shaker MA. Enhanced anticancer activity and oral bioavailability of ellagic acid through encapsulation in biodegradable polymeric nanoparticles. Int J Nanomed. 2017;12:7405.

68. Blasco C, Picó Y. Determining nanomaterials in food. TrAC, Trends Anal Chem. 2011;30(1):84-99.

69. Admiistration UFaD. [2021]. https://www.fda.gov/food/food-additivespetitions/food-additive-status-list\#ftnS. Accessed 21 Apr 2021.

70. Diab R, Canilho N, Pavel IA, Haffner FB, Girardon M, Pasc A. Silica-based systems for oral delivery of drugs, macromolecules and cells. Adv Colloid Interface Sci. 2017;249:346-62.

71. Kim MI, Kim J, Lee J, Jia H, Na HB, Youn JK, et al. Crosslinked enzyme aggregates in hierarchically-ordered mesoporous silica: a simple and effective method for enzyme stabilization. Biotechnol Bioeng. 2007;96(2):210-8.

72. Abbaraju PL, Kumar Meka A, Jambhrunkar S, Zhang J, Xu C, Popat A, et al. Floating tablets from mesoporous silica nanoparticles. J Mater Chem B. 2014;2(47):8298-302.

73. Carino IS, Pasqua L, Testa F, Aiello R, Puoci F, lemma F, et al. Silicabased mesoporous materials as drug delivery system for methotrexate release. Drug Delivery. 2007;14(8):491-5.

74. Tan HW, Mo H-Y, Lau AT, Xu Y-M. Selenium species: current status and potentials in cancer prevention and therapy. Int J Mol Sci. 2019;20(1):75.

75. Aldosary BM, Sutter ME, Schwartz M, Morgan BW. Case series of selenium toxicity from a nutritional supplement. Clin Toxicol. 2012;50(1):57-64.

76. Sonkusre P. Specificity of biogenic selenium nanoparticles for prostate cancer therapy with reduced risk of toxicity: an in vitro and in vivo study. Front Oncol. 2020;9:1541.

77. Mandracchia D, Trapani A, Tripodo G, Perrone MG, Giammona G, Trapani $\mathrm{G}$, et al. In vitro evaluation of glycol chitosan based formulations as oral delivery systems for efflux pump inhibition. Carbohyd Polym. 2017:166:73-82.

78. Smith J, Wood E, Dornish M. Effect of chitosan on epithelial cell tight junctions. Pharm Res. 2004:21(1):43-9.

79. Ranaldi G, Marigliano I, Vespignani I, Perozzi G, Sambuy Y. The effect of chitosan and other polycations on tight junction permeability in the human intestinal Caco-2 cell line. J Nutr Biochem. 2002;13(3):157-67.

80. Hong S-C, Yoo S-Y, Kim H, Lee J. Chitosan-based multifunctional platforms for local delivery of therapeutics. Mar Drugs. 2017;15(3):60. 
81. Chronopoulou L, Massimi M, Giardi MF, Cametti C, Devirgiliis LC, Dentini $M$, et al. Chitosan-coated PLGA nanoparticles: a sustained drug release strategy for cell cultures. Colloids Surf, B. 2013;103:310-7.

82. Biswas S, Chattopadhyay M, Sen KK, Saha MK, Maji HS. Structure-toxicity relationship of chemically modified chitosan as an Oral protein drug delivery carrier. J Pharmaceutical Sci Pharmacol. 2014;1 (2):131-40.

83. Eftekhari RB, Maghsoudnia N, Samimi S, Dorkoosh FA. Application of chitosan in oral drug delivery. Functional Chitosan: Springer; 2019. p. 43-73.

84. Raja MA, Zeenat S, Arif M, Liu C. Self-assembled nanoparticles based on amphiphilic chitosan derivative and arginine for oral curcumin delivery. Int J Nanomed. 2016;11:4397.

85. Zhang L, Shen Y, Qiu L. Loading docetaxel in $\beta$-cyclodextrin-based micelles for enhanced oral chemotherapy through inhibition of P-glycoprotein mediated efflux transport. RSC Adv. 2017;7(42):26161-9.

86. Calleja P, Espuelas S, Vauthier C, Ponchel G, Irache JM. Controlled release, intestinal transport, and oral bioavailablity of paclitaxel can be considerably increased using suitably tailored pegylated poly (anhydride) nanoparticles. J Pharm Sci. 2015;104(9):2877-86.

87. Sarmah JK, Bhattacharjee SK, Roy S, Mahanta R, Mahanta R. Biodegradable guar gum nanoparticles as carrier for tamoxifen citrate in treatment of breast cancer. J Biomater Nanobiotechnol. 2014;5(04):220.

88. Clark MA, Hirst BH, Jepson MA. Lectin-mediated mucosal delivery of drugs and microparticles. Adv Drug Deliv Rev. 2000;43(2-3):207-23.

89. Liu H, Tang R, Pan WS, Zhang Y, Liu H. Potential utility of various protease inhibitors for improving the intestinal absorption of insulin in rats. J Pharm Pharmacol. 2003;55(11):1523-9.

90. Langer K, Anhorn M, Steinhauser I, Dreis S, Celebi D, Schrickel N, et al. Human serum albumin (HSA) nanoparticles: reproducibility of preparation process and kinetics of enzymatic degradation. Int J Pharm. 2008;347(1-2):109-17.

91. Tan YL, Ho HK. Navigating albumin-based nanoparticles through various drug delivery routes. Drug Discovery Today. 2018;23(5):1108-14.

92. Chang C, Wang T, Hu Q, Zhou M, Xue J, Luo Y. Pectin coating improves physicochemical properties of caseinate/zein nanoparticles as oral delivery vehicles for curcumin. Food Hydrocolloids. 2017;70:143-51.

93. Golla K, Cherukuvada Bhaskar FA, Kondapi AK. A target-specific oral formulation of doxorubicin-protein nanoparticles: efficacy and safety in hepatocellular cancer. J Cancer. 2013;4(8):644.

94. Thanos C, Sandor M, Jong Y, Jacob J, Yip K-P, Harper J, et al. Interspecies uptake of polymeric microspheres. MRS Online Proc Library (OPL). 1998. https://doi.org/10.1557/PROC-550-65.

95. Planas JM, Alfaras I, Colom H, Juan ME. The bioavailability and distribution of trans-resveratrol are constrained by $\mathrm{ABC}$ transporters. Arch Biochem Biophys. 2012;527(2):67-73.

96. Acharya DP, Sanguansri L, Augustin MA. Binding of resveratrol with sodium caseinate in aqueous solutions. Food Chem. 2013;141(2):1050-4.

97. Bourassa P, Bariyanga J, Tajmir-Riahi H. Binding sites of resveratrol, genistein, and curcumin with milk $a$-and $\beta$-caseins. J Phys Chem B. 2013;117(5):1287-95.

98. Peñalva R, Morales J, González-Navarro CJ, Larrañeta E, Quincoces G, Peñuelas I, et al. Increased oral bioavailability of resveratrol by its encapsulation in casein nanoparticles. Int J Mol Sci. 2018;19(9):2816.

99. Goodman BE. Insights into digestion and absorption of major nutrients in humans. Adv Physiol Educ. 2010;34(2):44-53.

100. Wang T, Luo Y. Biological fate of ingested lipid-based nanoparticles: current understanding and future directions. Nanoscale. 2019;11(23):11048-63.

101. Ren T, Wang Q, Xu Y, Cong L, Gou J, Tao X, et al. Enhanced oral absorption and anticancer efficacy of cabazitaxel by overcoming intestinal mucus and epithelium barriers using surface polyethylene oxide (PEO) decorated positively charged polymer-lipid hybrid nanoparticles. J Control Release. 2018:269:423-38.

102. Yu F, Ao M, Zheng X, Li N, Xia J, Li Y, et al. PEG-lipid-PLGA hybrid nanoparticles loaded with berberine-phospholipid complex to facilitate the oral delivery efficiency. Drug Delivery. 2017;24(1):825-33.

103. Pund S, Borade G, Rasve G. Improvement of anti-inflammatory and antiangiogenic activity of berberine by novel rapid dissolving nanoemulsifying technique. Phytomedicine. 2014;21(3):307-14.

104. Baek J-S, Cho C-W. Surface modification of solid lipid nanoparticles for oral delivery of curcumin: Improvement of bioavailability through enhanced cellular uptake, and lymphatic uptake. Eur J Pharm Biopharm. 2017;117:132-40.

105. Venkateswarlu V, Manjunath K. Preparation, characterization and in vitro release kinetics of clozapine solid lipid nanoparticles. J Control Release. 2004;95(3):627-38.

106. Venishetty VK, Chede R, Komuravelli R, Adepu L, Sistla R, Diwan PV. Design and evaluation of polymer coated carvedilol loaded solid lipid nanoparticles to improve the oral bioavailability: a novel strategy to avoid intraduodenal administration. Colloids Surf, B. 2012:95:1-9.

107. Madan J, Pandey RS, Jain V, Katare OP, Chandra R, Katyal A. Poly (ethylene)glycol conjugated solid lipid nanoparticles of noscapine improve biological half-life, brain delivery and efficacy in glioblastoma cells. Nanomed Nanotechnol Biol Med. 2013;9(4):492-503.

108. Porter CJ,Charman WN. Transport and absorption of drugs via the lymphatic system. Adv Drug Delivery Rev. 2001;50:S1-2.

109. Han L, Tang C, Yin C. Oral delivery of shRNA and siRNA via multifunctional polymeric nanoparticles for synergistic cancer therapy. Biomaterials. 2014;35(15):4589-600

110. Ball RL, Bajaj P,Whitehead KA. Oral delivery of siRNA lipid nanoparticles: fate in the GI tract. Sci Rep. 2018;8(1):1-12.

111. Berg RD, Garlington AW. Translocation of certain indigenous bacteria from the gastrointestinal tract to the mesenteric lymph nodes and other organs in a gnotobiotic mouse model. Infect Immun. 1979;23(2):403-11.

112. Prescott $R$, Harris $M$, Banerjee SS. Fungal infections of the small and large intestine. J Clin Pathol. 1992;45(9):806-11.

113. Loessner $\mathrm{H}$, Weiss S. Bacteria-mediated DNA transfer in gene therapy and vaccination. Expert Opin Biol Ther. 2004;4(2):157-68.

114. Taylor PR, Tsoni SV, Willment JA, Dennehy KM, Rosas M, Findon H, et al. Dectin-1 is required for $\beta$-glucan recognition and control of fungal infection. Nat Immunol. 2007;8(1):31-8.

115. Zhou X, Zhang X, Han S, Dou Y, Liu M, Zhang L, et al. Yeast microcapsulemediated targeted delivery of diverse nanoparticles for imaging and therapy via the oral route. Nano Lett. 2017;17(2):1056-64.

116. Mowat AM. Anatomical basis of tolerance and immunity to intestinal antigens. Nat Rev Immunol. 2003;3(4):331-41.

117. Serradell MC, Rupil LL, Martino RA, Prucca CG, Carranza PG, Saura A, et al. Efficient oral vaccination by bioengineering virus-like particles with protozoan surface proteins. Nat Commun. 2019;10(1):1-15.

118. Hu Q, Wu M, Fang C, Cheng C, Zhao M, Fang W, et al. Engineering nanoparticle-coated bacteria as oral DNA vaccines for cancer immunotherapy. Nano Lett. 2015;15(4):2732-9.

119. Betker JL, Angle BM, Graner MW, AnchordoquyTJ.The potential of exosomes from cow milk for oral delivery. J Pharm Sci. 2019;108(4):1496-505.

120. Munagala R, Aqil F, Jeyabalan J, Gupta RC. Bovine milk-derived exosomes for drug delivery. Cancer Lett. 2016;371(1):48-61.

121. Vaswani K, Mitchell MD, Holland OJ, Qin Koh Y, Hill RJ, Harb T, et al. A method for the isolation of exosomes from human and bovine milk. J Nutr Metab. 2019. https://doi.org/10.1155/2019/5764740.

122. Izumi H, Kosaka N, Shimizu T, Sekine K, Ochiya T, Takase M. Bovine milk contains microRNA and messenger RNA that are stable under degradative conditions. J Dairy Sci. 2012;95(9):4831-41.

123. Agrawal AK, Aqil F, Jeyabalan J, Spencer WA, Beck J, Gachuki BW, et al. Milkderived exosomes for oral delivery of paclitaxel. Nanomed Nanotechnol Biol Med. 2017;13(5):1627-36.

124. Hoque M, Dave S, Gupta P, Saleemuddin M. Oleic acid may be the key contributor in the BAMLET-induced erythrocyte hemolysis and tumoricidal action. PLoS ONE. 2013;8(9):e68390.

125. Ghiasi MR, Rahimi E, Amirkhani Z, Salehi R. Leucine-rich repeat-containing G-protein coupled receptor 5 gene overexpression of the rat small intestinal progenitor cells in response to orally administered grape exosome-like nanovesicles. Adv Biomed Res. 2018;7:125.

126. Takeuchi I, Kamiki Y, Makino K. Therapeutic efficacy of rebamipideloaded PLGA nanoparticles coated with chitosan in a mouse model for oral mucositis induced by cancer chemotherapy. Colloids Surf B. 2018;167:468-73.

127. Gupta P, Singh M, Kumar R, Belz J, Shanker R, Dwivedi PD, et al. Synthesis and in vitro studies of PLGA-DTX nanoconjugate as potential drug delivery vehicle for oral cancer. Int J Nanomed. 2018;13(1):67. 
128. Fredi G, Simon F, Sychev D, Melnyk I, Janke A, Scheffler C, et al. Bioinspired polydopamine coating as an adhesion enhancer between paraffin microcapsules and an epoxy matrix. ACS Omega. 2020;5(31):19639-53.

129. Zhou Y, Zhu X, Lin S, Zhu C, Wu L, Chen R, et al. A novel nanoparticle preparation to enhance the gastric adhesion and bioavailability of xanthatin. Int J Nanomed. 2020;15:5073.

130. Kotelevets L, Chastre E, Caron J, Mougin J, Bastian G, Pineau A, et al. A squalene-based nanomedicine for oral treatment of colon cancer. Cancer Res. 2017;77(11):2964-75.

131. Xu J, Zhang Y, Xu J, Wang M, Liu G, Wang J, et al. Reversing tumor stemness via orally targeted nanoparticles achieves efficient colon cancer treatment. Biomaterials. 2019;216:119247.

132. O'Driscoll CM, Bernkop-Schnürch A, Friedl JD, Préat V, Jannin V. Oral delivery of non-viral nucleic acid-based therapeutics-do we have the guts for this? Eur J Pharm Sci. 2019;133:190-204.

133. Brayden DJ, Hill T, Fairlie D, Maher S, Mrsny R. Systemic delivery of peptides by the oral route: formulation and medicinal chemistry approaches. Adv Drug Deliv Rev. 2020;157:2-36.

134. Kongshaug N, Skolbekken J-A, Faxvaag A, Hofsli E. Cancer patients'perceived value of a smartphone app to enhance the safety of home-based chemotherapy: feasibility study. JMIR Format Res. 2021;5(1):e20636.

135. Marmorat T, Rioufol C, Ranchon F, Préau M. Encounters between medical and lay knowledge in therapeutic patient education. A qualitative study based on an oral chemotherapy program. Patient Educ Couns. 2020;103(3):537-43.

136. Lee J, Kang J, Kwon N-Y, Sivaraman A, Naik R, Jin S-Y, et al. Dual inhibition of P-gp and BCRP improves oral topotecan bioavailability in rodents. Pharmaceutics. 2021;13(4):559.

137. Fine-Shamir N, Beig A, Dahan A. Adequate formulation approach for oral chemotherapy: etoposide solubility, permeability, and overall bioavailability from cosolvent-vs. vitamin E TPGS-based delivery systems. Int J Pharm. 2021;597:120295

138. Liu M, Lai Z, Zhu L, Ding X, Tong X, Wang Z, et al. Novel amorphous solid dispersion based on natural deep eutectic solvent for enhancing delivery of anti-tumor RA-XII by oral administration in rats. Eur J Pharm Sci. 2021;166:105931.

139. Berardi A, Baldelli BF. Oral delivery of nanoparticles-let's not forget about the protein corona. Expert Opin Drug Deliv. 2019;16(6):563-6.

\section{Publisher's Note}

Springer Nature remains neutral with regard to jurisdictional claims in published maps and institutional affiliations.
Ready to submit your research? Choose BMC and benefit from:

- fast, convenient online submission

- thorough peer review by experienced researchers in your field

- rapid publication on acceptance

- support for research data, including large and complex data types

- gold Open Access which fosters wider collaboration and increased citations

- maximum visibility for your research: over 100M website views per year

At BMC, research is always in progress.

Learn more biomedcentral.com/submissions 